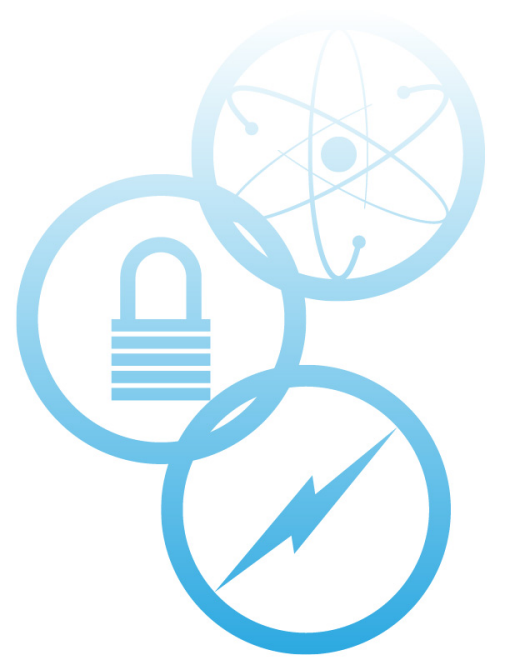

\title{
U-50Zr Microstructure and Property Assessment for LWR Applications
}

Geoffrey L. Beausoleil, Mahmut Nedim Cinbiz, Tiankai Yao, Yachun Wang, Fidelma Di Lemma, Cynthia Adkins, Tsvetoslav Pavlov, Walter J. Williams, Rongjie Song, Luca Capriotti

Idaho National Laboratory

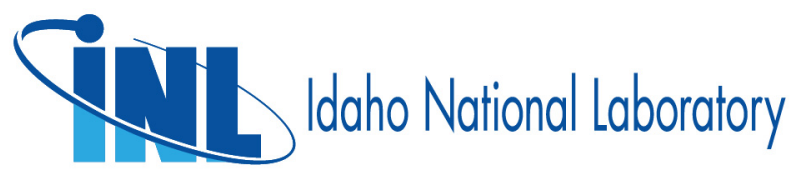




\section{DISCLAIMER}

This information was prepared as an account of work sponsored by an agency of the U.S. Government. Neither the U.S. Government nor any agency thereof, nor any of their employees, makes any warranty, expressed or implied, or assumes any legal liability or responsibility for the accuracy, completeness, or usefulness, of any information, apparatus, product, or process disclosed, or represents that its use would not infringe privately owned rights. References herein to any specific commercial product, process, or service by trade name, trade mark, manufacturer, or otherwise, does not necessarily constitute or imply its endorsement, recommendation, or favoring by the U.S. Government or any agency thereof. The views and opinions of authors expressed herein do not necessarily state or reflect those of the U.S. Government or any agency thereof. 


\section{U-50Zr Microstructure and Property Assessment for LWR Applications}

Geoffrey L. Beausoleil, Mahmut Nedim Cinbiz, Tiankai Yao, Yachun Wang, Fidelma Di Lemma, Cynthia Adkins, Tsvetoslav Pavlov, Walter J. Williams, Rongjie Song, Luca Capriotti

Idaho National Laboratory

September 2021

Idaho National Laboratory Nuclear Science and Technology Idaho Falls, Idaho 83415

http://www.inl.gov

Prepared for the U.S. Department of Energy Office of Nuclear Energy Under DOE Idaho Operations Office

Contract DE-AC07-05ID14517 
Page intentionally left blank 


\section{ABSTRACT, SUMMARY, FOREWORD, AND ACKNOWLEDGEMENTS}

This project provides an initial assessment and research recommendations of U-50 wt.\%Zr (U-50Zr) for its use as a light water reactor (LWR) fuel. This work based on the outcome of a recently funded exercise on the failure mode effects and analysis (FMEA) and the phenomena identification and ranking table (PIRT) to investigate high level nuclear fuel qualification metrics as derived by the United States Nuclear Regulatory Commission.

The current knowledge used for the FMEA and PIRT analysis is based on uranium dioxide (UO2) fuel for LWRs and limited performance data from metallic fuel form of U-10Zr used in sodium-cooled fast reactors. Furthermore, the current knowledge on the U50Zr fuel is insufficient to conduct quantitative analysis, and the FMEA and PIRT analysis for U-50Zr fuel consists of insufficient knowledge, data gaps, and educated qualitative forecasting of LWR behavior during operation and transients. FMEA and PIRT exercise has qualitatively identified immediate phenomena impacting the fuel performance. These immediate phenomena are (i) thermal and mechanical property measurements at LWR relevant temperatures, (ii) evolution of the pellet-cladding interaction (PCI) layer, and (iii) hydrogen effects on the formation PCI layer.

Thus, a preliminary survey was conducted to determine thermal properties such as thermal conductivity, thermal expansion, and neat capacity. The mechanical property survey consisted of determination of elastic modulus, hardness, apparent yield stress as a function of temperature using nanoindentation based techniques. Furthermore, the thermal creep of the U-50Zr was also informatively investigated using nanoindentation based techniques.

Data presented in this report provides a very first understanding of the U-50Zr fuel properties and potential PCI characteristics. Results also validated the very first FMEA and PIRT analysis that predicts likely fuel cladding behavior to the operating and transient conditions. Finally, results informed critical research areas for $\mathrm{U}-50 \mathrm{Zr}$.

The authors would like to acknowledge the Gateway for Accelerated Innovation in Nuclear (GAIN) for funding this effort along with Framatome Inc. for leading the initial FMEA and PIRT effort that prompted this work. Lastly, the authors would like to acknowledge the additional members of the PIRT and FMEA team from Idaho National Laboratory; Albert Casagranda, Piyush Sabharwal, Mitchell K. Meyer, Gilles J. Youinou, Kevan D. Weaver, Cliff Davis, and David W. Kammerman. 
Page intentionally left blank 


\section{CONTENTS}

ABSTRACT, SUMMARY, FOREWORD, AND ACKNOWLEDGEMENTS.............................iii

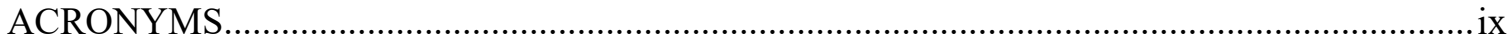

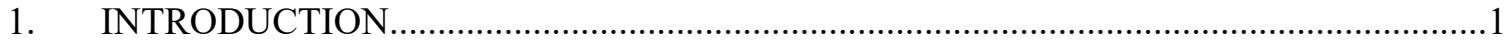

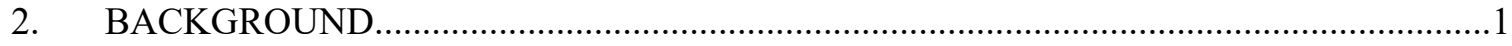

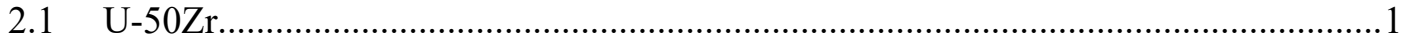

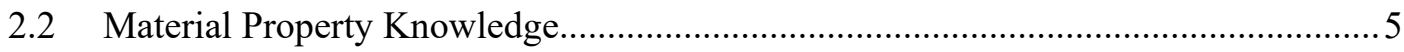

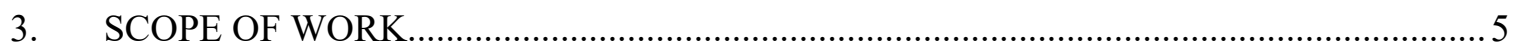

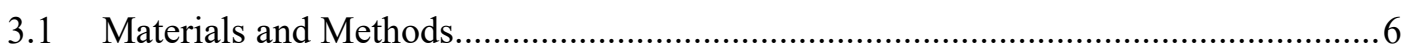

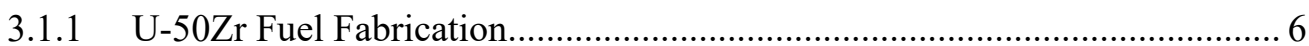

3.1.2 Zircaloy-4 Specimens and Hydriding....................................................... 7

3.1.3 Diffusion Couple Study........................................................................... 7

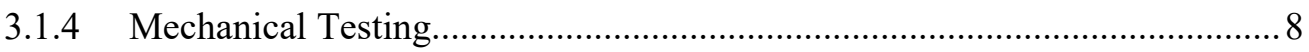

3.1.5 X-ray Diffraction and Electron Microscopy.............................................. 11

3.1.6 Thermophysical property characterization................................................ 11

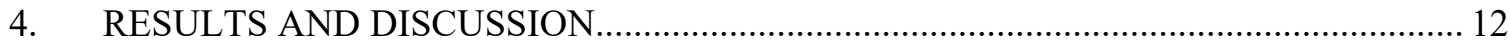

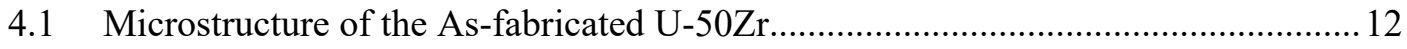

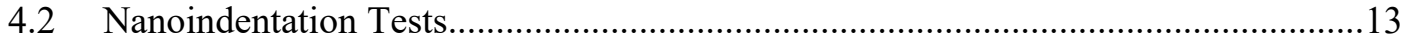

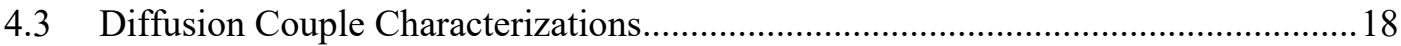

4.4 Thermophysical Property Characterizations........................................................... 22

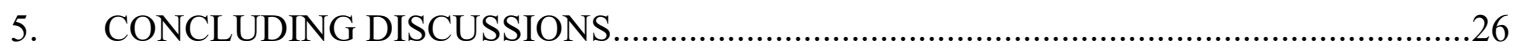

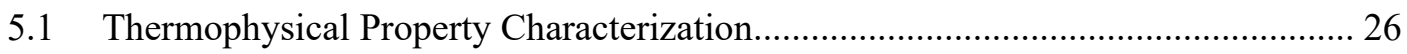

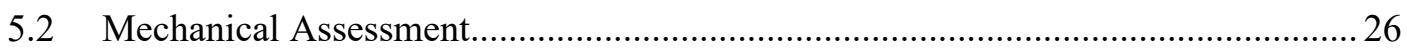

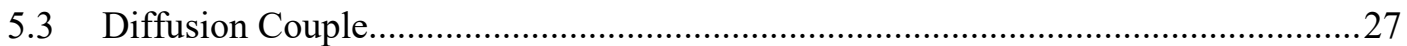

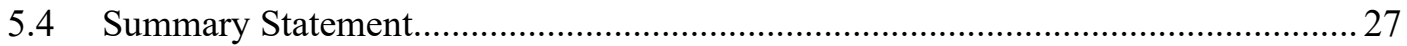

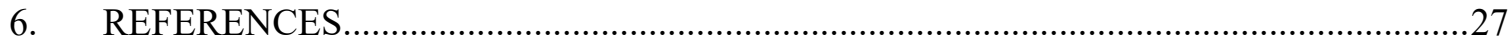

\section{FIGURES}

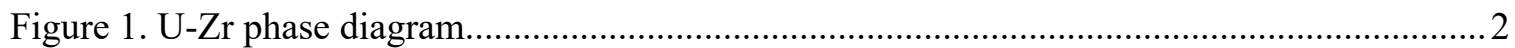

Figure 2. Fission gas bubbles in $\mathrm{U}-\mathrm{Zr}$ alloys. The left micrograph shows bubble formation in a-U,

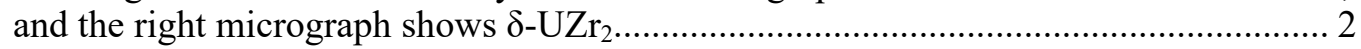

Figure 3. Thermal conductivity of $\mathrm{UO}_{2}$ and chosen $\mathrm{UZr}$ compositions....................................... 4

Figure 4. A casted U-50Zr pin with the casting mold half disassembled (a); the pin is held by a

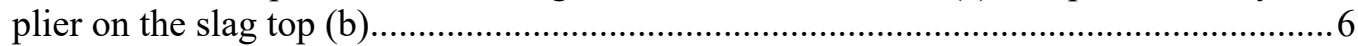

Figure 5. (a) Physical installation and (b) schematic of the hydriding system............................... 7 
Figure 6. Experimental setup for the diffusion couple experiment. The diffusion couple jigs were sealed in a quartz ampoule as shown by inserted image - optical microscopy of the diffusion couple set up. U-50Zr is sandwiched by Ta sheets and Zircaloy-4 alloy; excessive amount of Ta sheets was used on the bottom to isolate reaction between Kovar jig and diffusion couple samples.

Figure 7. Typical nanoindentation load displacement curve of U-50Zr where the maximum load was $100 \mathrm{mN}$ at room temperature. The radius of the indenter was $50 \mu \mathrm{m}$.

Figure 8. Typical nanoindentation creep force displacement curve of $\mathrm{U}-50 \mathrm{Zr}$ at $200^{\circ} \mathrm{C}$. Specimen was held at constant load of $100 \mathrm{mN}$. The radius of the indenter was $50 \mu \mathrm{m}$..... 10

Figure 9. SEM image of the as-fabricated fuel, showing features for casted microstructure with columnar grains..

Figure 10. XRD spectrum and indexing against theoretical peak positions for $\delta$-UZr2 and $\alpha-Z r$.

Figure 11. Forward scattered electron image (a) of the area where electron backscattered electron diffraction patterns were collected and analyzed to produce the orientation mapping of hexagonal $\mathrm{UZr}_{2}$ phase (b). Inside each parent bcc grain, there are two dominant orientations for the hexagonal phase. Some grains do not have patterns recognizable for hexagonal $\mathrm{UZr}_{2}$ phase.

Figure 12. Spherical indents in U-50Zr microstructure.

Figure 13. (a) Temperature-dependent hardness and (b) elastic modulus of U-50Zr.

Figure 14. Yield stress predictions using ECM model with different initial yield stress guesses.

Figure 15. Temperature-dependent ECM-estimated yield stress of U-50Zr.

Figure 16. Indentation creep strain and creep rate at $200^{\circ} \mathrm{C}$, indenter radius: $50 \mu \mathrm{m}, \mathrm{P}_{\max }=100 \mathrm{mN}$.

Figure 17. Analytical transmission electron micrograph of U-50Zr showing the microstructure beneath the indenter (i) shows the creep-induced dislocation sub-structuring with respect to a zirconium precipitate, (ii) shows twinned regions and the dislocation.

Figure 18. SEM images of the interaction between U-50Zr and Zircaloy-4 sample after various days hold at $375^{\circ} \mathrm{C}$ for 0 days (a); 1 day (b), 7 days (c), and 28 days (d) with higher magnification SEM images of the interface region inserted at bottom left corner. Gaps between the $\mathrm{Zr}-4$ and the $\mathrm{U}-50 \mathrm{Zr}$ are ex

Figure 19. SEM images of the interaction between U-50Zr and hydrided Zircaloy-4 sample after 14 days hold at $375^{\circ} \mathrm{C}$, showing the formation of a $200 \mathrm{~nm}$ thick layer of interaction with possible U-rich band at the interface (a-d). However, SEM-EDS could not resolve the chemical variation across the interaction (e-f). Orange arrows indicates hydrides in the Zircaloy-4.

Figure 20. Transmission electron microscopy-based selected-area electron diffraction pattern indexing of the phase in the region of diffusion couple interface; (a) overview of TEM sample with site specific FIB sample preparation; (b) the Zircaloy-4 crystalizes in hexagonal crystal structure with $\mathrm{a}=3.23 \AA$ and $\mathrm{c}=5.15 \AA$; (c) U-50Zr also crystalizes in hexagonal crystal structure with a $=5.03$; $\AA$ and $\mathrm{c}=3.08 \AA$; (d-e) shows the precipitates, circled in (a), is $\alpha-Z r$ with $\mathrm{a}=3.23 \AA$ and $\mathrm{c}=5.15 \AA$. The gap in the middle is formed during cooling due to weak bonding. 
Figure 21. Scanning TEM element mapping across the diffusion interaction region of the 28-day sample. Results indicate the formation of a U-rich band. Those $U$ phases exists as particles, columnar grains, and precipitates. $\mathrm{Fe}, \mathrm{Cr}$, and $\mathrm{Sn}$ has little contribution. Oxygen has slightly higher concentration at the outmost interaction layer.

Figure 22. (a) Overview of TEM sample prepared from a 28-day diffusion couple shows evident interaction inside the U-50Zr side; (b) high-angle annular dark field image shows the interaction region can be divided into four layers with layer 1 featured by (Zr0.7U0.25Sn0.03Cr0.02)O2 nanocrystals, layer 2 by high-density $\alpha$-U particles in a Zr matrix; layer 3 by columnar $\alpha-U$ grains growing towards the interface, and layer 4 with $\alpha$-U precipitates embedded in U-50Zr matrix with subdivided grains.....

Figure 23. A comparison of 7 days (a-d) and 28 days (e-f) diffusion couples. Although columnar grains also formed on the diffusion interface (as highlighted in b), it shows little chemical variation compared with 28-day sample. However, the U-rich particles in a $\mathrm{Zr}$-rich matrix is clearly shown in a band $30 \mathrm{~nm}$ wide, much narrower than 28-day sample

Figure 24. DSC signal as a function of temperature showing upon heating (top curve) and cooling (bottom curve). The onset and end temperatures have been identified for the corresponding phase transformations as well as the respective formation enthalpies (presented as peak areas)

Figure 25 . Thermal diffusivity of as-cast $\mathrm{U}-50 \mathrm{wt} . \% \mathrm{Zr}$ as a function of temperature. The measurements are performed upon heating.

Figure 26. Specific heat capacity of as-cast U-50wt.\% $\mathrm{Zr}$ as a function of temperature. The temperatures at which phase transitions occur have been omitted. The measurements are performed upon heating...

Figure 27. Thermal expansion of as-cast U-50 wt.\% $\mathrm{Zr}$ as a function of temperature. The measurements are performed upon heating.

Figure 28. Thermal conductivity of as-cast $\mathrm{U}-50 \mathrm{wt} . \% \mathrm{Zr}$ as a function of temperature. The measurements are performed upon heating. 26

\section{TABLES}

Table 1. Material properties comparison of $\mathrm{UO}_{2}$ and $\mathrm{Uzr}[6-10]$.

Table 2. Temperature-dependent average hardness and elastic modulus of U-50Zr via nanoindentation 14

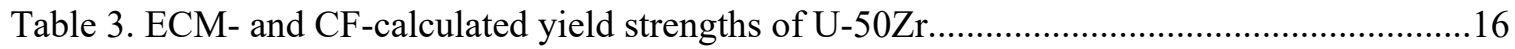

Table 4. Creep-curve fit results for various experiments. 
Page intentionally left blank 


\section{ACRONYMS}

DOE Department of Energy

DSC Differential-scanning calorimetry

DU Depleted uranium

ECM Expanding cavity model

EDM Electron discharge machined

EDS Energy dispersive x-ray spectroscopy

FIB Focused-ion beam

FMEA Failure mode effects and analysis

GAIN Gateway for Accelerated Innovation in Nuclear

IMCL Irradiated materials characterization laboratory

LFA Laser-flash analysis

LOCA Loss of coolant accident

LWR Light-water reactor

NE Nuclear Energy

PCMI Pellet-clad mechanical interaction

PIRT Phenomenon identification and ranking tables

PWR Pressurized-water reactor

R\&D Research and development

SAED Selected-area diffraction

SEM Scanning electron microscopy

TEM Transmission electron microscopy

XRD X-ray diffraction 
Page intentionally left blank 


\section{INL Analysis and Recommendations to Framatome FMEA and PIRT for Metallic Fuel}

\section{INTRODUCTION}

As part of the progression of the nuclear industry and the advancement of nuclear technologies, new fuel designs are being investigated to further improve the operational and transient margins of the current light-water reactor (LWR) fleet. The fuel of interest for this project is the metallic fuel system based on uranium-zirconium (U-Zr) compositions. Historically, metallic fuel has typically been used in fast reactor concepts. As part of the research to develop and improve a proposed fuel type, basic material properties are being assessed for a U-Zr alloy fuel to be used within LWR applications. Specifically, a $50 \mathrm{wt} \%$ alloy (U-50ZR) will be investigated for its thermal-mechanical properties as well as its potential interactions with zirconium alloy (zircaloy) cladding and hyrdrided cladding. The findings from the experimental efforts can be used to guide future research and development (R\&D) and qualification efforts.

\section{BACKGROUND}

The goal of the Gateway for Accelerated Innovation in Nuclear (GAIN) program is to accelerate the innovation and application of advanced nuclear technologies. GAIN Nuclear Energy (NE) voucher recipients do not receive direct financial awards. Instead, the vouchers provide access to national laboratory capabilities at no cost to the voucher recipients. Idaho National Laboratory (INL), located in Idaho Falls, Idaho, is the partner facility for this award. Through the GAIN initiative, the U.S. Department of Energy (DOE) recently announced that Framatome Inc., headquartered in Lynchburg, Virginia, will receive a Fiscal Year 2019 GAIN NE voucher to develop failure mechanisms using a failure mode effects and analysis (FMEA) for an advanced fuel design involving extruded, solid metallic fuel for LWR applications. Phenomena associated with these failure mechanisms were also identified and ranked according to impact and understanding (via phenomenon identification and ranking tables [PIRTs]). Following the FMEA and PIRT activities (previously reported), material investigations were performed in order to better guide future fuel $R \& D$ and qualification efforts. It is important to note the results of the FMEA and PIRT were heavily based upon assumptions made from experience with similar fuel alloys and projecting fuel behaviors from non-LWR irradiation experience (i.e., the use of U-10Zr in sodium fast reactors, SFRs).

The projection of fuel performance phenomena of high-zircaloy fuel into low-temperature thermal spectrum reactor conditions from that of low-zircaloy fuel at high-temperature fast reactor conditions creates significant uncertainty in the conclusions. As a result, it became imperative for this study that basic material properties be assessed. While some work has been done in the past, the data in open literature that is necessary to develop basic performance models and predict performance is limited. Much of it is also very dated and needs significant updating using more modern and advanced characterization methods. This project has therefore taken on the opportunity to perform basic material characterization studies on U-50Zr (50 wt.\% Zr) alloys. These properties include microstructural, mechanical, and thermal properties.

\section{$2.1 \mathrm{U}-50 \mathrm{Zr}$}

The U-50Zr fuel design of interest for this project has the following properties:

1. Alloy fuel will be composed of $\mathrm{U}$ and $\sim 50 \mathrm{wt} . \% \mathrm{Zr}(72.29 \mathrm{at} \% \mathrm{Zr}$ ). This is commonly referred to as the delta phase of U-Zr, as shown in Figure 1.

2. The fuel will be clad in an equivalent manner to the traditional $\mathrm{UO}_{2}$ design by using zircaloy cladding (e.g., a $\mathrm{Zr}-\mathrm{Nb}$ variant, such as M5 ${ }^{\mathrm{TM}}$ ).

3. The rods will be arranged in a rectangular array supported and positioned by spacers, as is typical within a fuel assembly bundle that maintains the position and location of the 24 guide tubes plus an 
instrument tube of the current U.S. pressurized-water reactor (PWR) $17 \times 17$ design $\mathrm{UO}_{2}$ fuel assembly. This is important for general consideration but has little impact to the nature of this report.

As can be seen in the phase diagram in Figure 1, a traditional $U-10 \mathrm{Zr}$ fuel operated in the $a+\delta$ phase and much of the research performed on the U-Zr properties was focused on this mixed phase system. $\mathrm{U}-50 \mathrm{Zr}$ fuel will operate in the $\delta-\mathrm{UZr}_{2}$ phase (AlB2 type crystal structure [1]), and research in this phase region is limited. An initial advantage with this higher $\mathrm{Zr}$ content is less swelling and expected fission gas release under basic conditions. The swelling rate had a rate of $1 \%$ volume increase per 1\% FIMA [2].

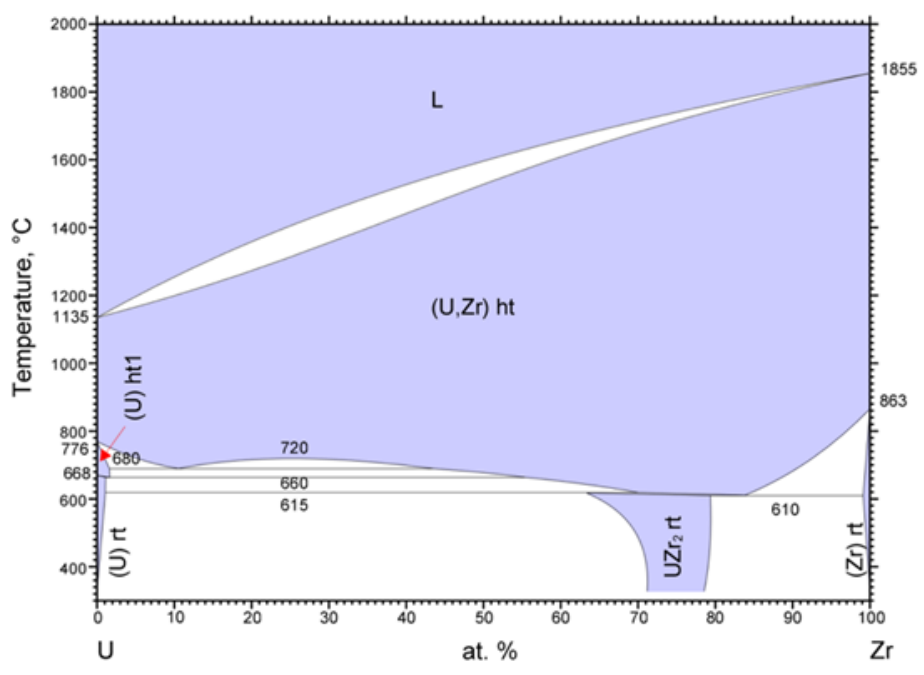

Figure 1. U-Zr phase diagram.

In the experimental work by Ahn, Irukuvarghula, and McDeavitt ${ }^{4}, \mathrm{U}-0.1 \mathrm{Zr}$ and U-40Zr were irradiated using a $140-\mathrm{keV} \mathrm{He}^{+}$ion beam. These alloys reside in the $\mathrm{a}+\delta$ phase, and the purpose of the study was to see the effect of irradiation compared to the amount of a-U phase and $\delta-U Z r_{2}$ phase in the alloy. In U-0.1Zr, several large bubbles $(<\sim 70 \mathrm{~nm})$ with a higher concentration of a-U and bubble leakage were both present. In contrast, for U-40Zr, a number of small $(\sim 6 \mathrm{~nm})$ voids were observed and remained stationary with higher amounts of the $\delta-\mathrm{UZr}_{2}$ phase in the alloy. Figure 2 shows these results for the irradiation of these alloys. This study helped to affirm that a-U is more radiation susceptible than $\delta-\mathrm{UZr}_{2}$ [3]. This also gives greater evidence to the smaller degree of swelling and fission gas release in U-50Zr.

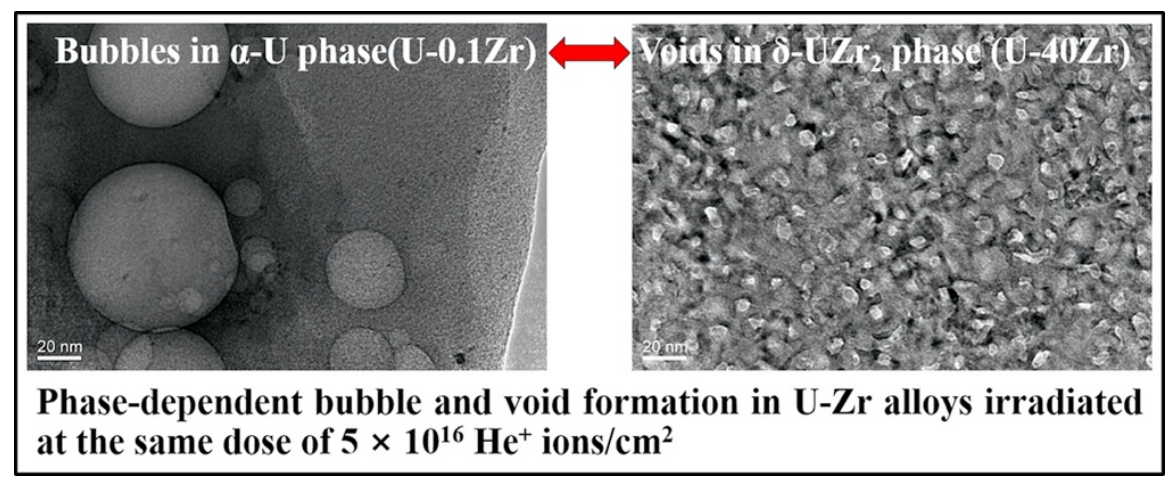

Figure 2. Fission gas bubbles in U-Zr alloys. The left micrograph shows bubble formation in a-U, and the right micrograph shows $\delta-\mathrm{UZr}_{2}$. 
Another advantage of using a metallic fuel is that it has a higher thermal conductivity than $\mathrm{UO}_{2}$. In Figure 3, a graph shows this relationship as a function of temperature for $\mathrm{UO}_{2}$ and two different compositions of U-Zr. The correlation for U-Zr was calculated using the Galloway correlation used for Bison modeling and accounts for $\mathrm{Zr}$ concentration in the $\mathrm{U}-\mathrm{Zr}$ composition [4]. The $\mathrm{UO}_{2}$ correlation was recommended by the International Nuclear Safety Center [5]. With the higher thermal conductivity, the fuel can also operate at a lower temperature. This allows for the gaseous fission products to act like solids and remain immobile within the metallic fuel. 
Table 1 shows a comparison of the material properties of $\mathrm{U}-\mathrm{Zr}$ and $\mathrm{UO}_{2}$, respectively.

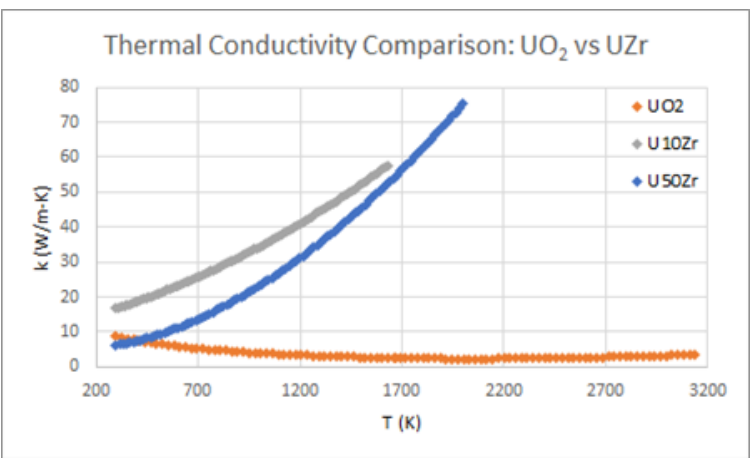

Figure 3. Thermal conductivity of $\mathrm{UO}_{2}$ and chosen $\mathrm{UZr}$ compositions. 
Table 1. Material properties comparison of $\mathrm{UO}_{2}$ and $\mathrm{Uzr}[6-10]$.

\begin{tabular}{|l|c|c|}
\hline \multicolumn{1}{|c|}{ Fuel Comparison } & Metallic Fuel (U-10Zr) & Metallic Fuel (U-50Zr) \\
\hline Theoretical Density $\left(\mathrm{g} / \mathrm{cm}^{3}\right)$ & 15.94 & 9.64 \\
\hline Solidus Temperature $\left({ }^{\circ} \mathrm{C}\right)$ & 1,356 & 1,725 \\
\hline Uranium Loading $(\mathrm{wt} . \%)$ & 90.00 & 50.00 \\
\hline Operating Temperature $\left({ }^{\circ} \mathrm{C}\right)$ & $<800^{2}$ & $<800^{1}$ \\
\hline
\end{tabular}

1. This is the average peak centerline temperature of metal fuels tested in the EBR-II sodium fast reactor.

\subsection{Material Property Knowledge}

As stated, the lack of research on U-50Zr results in significant gaps in the general understanding of material properties. It is critical for any fuel system to have a thorough understanding of the fuelcladding-coolant compatibility, possible chemical interactions, thermomechanical behaviors of the fuel and cladding, and how these effects interact. These properties are typically represented in a coupled fashion through fuel performance models that can represent the anticipated behavior of the materials within the fuel system during normal operations, anticipated operational occurrences, and even unanticipated occurrences, such as transient conditions (e.g., loss of coolant accident [LOCA] and nonLOCA events). The phenomena that fuel performance models communicate are also not represented by single properties (also referred to as separate effects) but rather an integral relationship of multiple properties. The typical material properties that require thorough understanding are as follows:

- Mechanical properties

- Elastic modulus

- Poisson's ratio

- Yield stress

- Creep rate (active mechanisms, activation energy, stress exponent, diffusion coefficients, etc.)

- Thermal properties

- Thermal conductivity

- Specific heat

- Thermal expansion

- Chemical interactions and resultant phases

- Hydriding

- Fuel-cladding chemical interactions

- Irradiation effects

- Defect transport (e.g., vacancy and interstitials)

- Diffusion kinetics

- Swelling (solid and gaseous)

- Fission gas release (FGR)

- Radiation enhanced creep

- Effects on both mechanical and thermal properties

\section{SCOPE OF WORK}

Scope of the current study is to perform a preliminary survey on U-50Zr fuel candidate. This survey includes thermophysical and selected mechanical properties of the fuel and any potential species diffusion at fresh U-50Zr and Zircaloy-4 (both as received and hydrided) contact interface. Performed activities are: 
U-50Zr fuel preparation: fuel samples were prepared using arc-melting and drop-casting techniques in an inert glove box. The fabricated specimens were also characterized using scanning electron microscopy and x-ray diffraction to confirm final $\mathrm{U}-50 \mathrm{Zr}$ phase and anticipated microstructure.

(ii) Thermophysical assessment of the $\mathbf{U}-50 Z \mathbf{r}$ fuel: thermal property assessment included laser-flash analysis (LFA), differential-scanning calorimetry (DSC), and dilatometry experiments to determine thermal diffusivity, heat capacity, and thermal expansion of $\mathrm{U}-50 \mathrm{Zr}$, respectively.

(iii) Mechanical assessment of the $\mathbf{U}-\mathbf{5 0 Z r}$ fuel: mechanical assessment included the determination of elastic modulus and prediction of yield stress using nanoindentation techniques. In addition, constant load experiments were also conducted to investigate thermal creep-like deformation of the U-50Zr fuel. Nanoindentation experiments were performed at ambient and elevated temperatures. Selected locations of the specimen were also characterized via transmission electron microscopy to predict the governing creep mechanisms.

(iv) Diffusion couple study: diffusion couples were prepared to assess the potential interactions between the fuel and the cladding. Therefore, diffusion couples made of U-50Zr and Zircaloy-4 were prepared. To investigate any impact of hydrogen, some Zircaloy-4 samples were hydrogen-charged (hydrided). For hydrogen charging, a mass flow-rate-controlled hydriding system was built. The diffusion couples were subjected to heat treatments at LWRrelevant temperature up to 24 days, and diffusion couples were analyzed using electron microscopy techniques.

\subsection{Materials and Methods}

\subsubsection{U-50Zr Fuel Fabrication}

U-50Zr fuel samples were fabricated via arc-melting and drop-casting [11] using the legacy EBR-II depleted uranium (DU) feedstock and zirconium with the purity of $99.9 \%$. The starting DU included iron $(\mathrm{Fe})$, aluminum $(\mathrm{Al})$, silicon $(\mathrm{Si})$, and manganese $(\mathrm{Mn})$ as major impurities. The total impurity weight was less than $0.005 \mathrm{wt} \%$ for the DU. For each melt, DU and Zr weight ratio was 1:1, and the total weight of the material was $\sim 20 \mathrm{~g}$ for arc-melting. DU and Zr were separately melted into an ingot in an arc-melter that operated under high-purity argon (Ar) to avoid oxidation. The overall glovebox, where arc-melting was performed, reached $<5 \mathrm{ppm}$ of $\mathrm{O}_{2}$ prior to the arc-melting. The arc-melting was repeated five times on the ingot to improve compositional homogeneity. The melted ingot was drop casted into a $5 \mathrm{~mm}$ diameter pin (see Figure 4a). To ease the melt flow, the space underneath the cast hearth that holds melt was held at a negative pressure of $0.5 \mathrm{MPa}$. Once the melt reached homogeneity, the gate between cast hearth and vacuumed chamber was opened, and the melt-drop was casted. Five pins were cast at the same time using same materials feedstock.

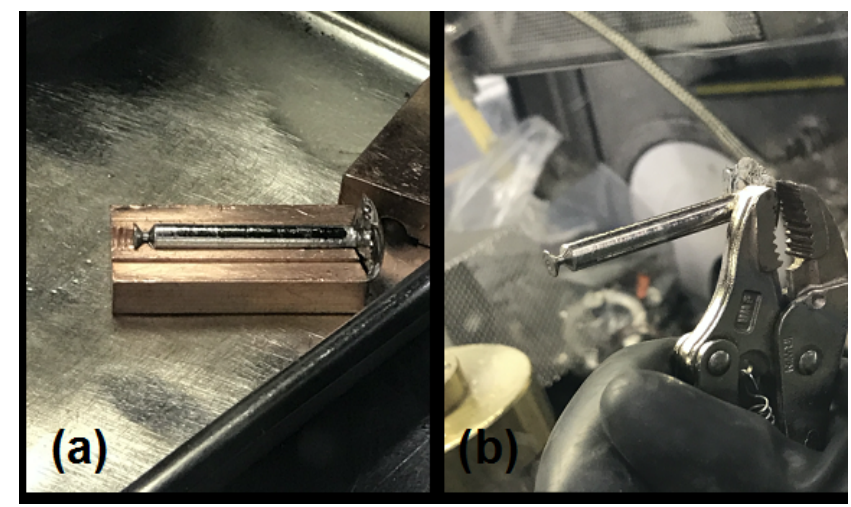

Figure 4. A casted U-50Zr pin with the casting mold half disassembled (a); the pin is held by a plier on the slag top (b). 
Casted pins were wrapped in tantalum (Ta) film and sealed in quartz ampoule under vacuum before being loading into a box furnace for heat treatment to produce delta phase. The furnace temperature increased to $635^{\circ} \mathrm{C}$ in 0.5 hour and hold at $635^{\circ} \mathrm{C}$ for 4 hours before furnace cooled down to $550^{\circ} \mathrm{C}$ at which temperature the sample were annealed for 2 weeks to produce hexagonal $\delta$ phase $\mathrm{UZr}_{2}$. Asfabricated samples were characterized using $\mathrm{x}$-ray diffraction (XRD) and scanning electron microscopy to confirm the existing $\delta \mathrm{UZr}_{2}$ phase. After parent material fabrication, samples for diffusion couple investigation, nanoindentation, and thermal analysis were sectioned using a low-speed saw.

\subsubsection{Zircaloy-4 Specimens and Hydriding}

Zircaloy-4 were obtained from Intec's legacy stock in the plate form with a thickness of $2.54 \mathrm{~mm}$. Samples were electron discharge machined (EDM) cut into small squares with the nominal width of $5 \mathrm{~mm}$. For hydriding, a mass flow-controlled hydrogen charging system was built as shown in Figure 5. Prior to hydriding, specimens' surface was lightly grinded to remove the oxide layer. Specimens were placed in the alumina tube furnace in the uniform temperature zone of the tube furnace. The specimen temperature was measured using a K-type thermocouple that was placed directly adjacent to the specimens. The chamber was purged with pure Ar to remove $\mathrm{O}$ from the chamber prior to hydriding. After Ar purge, $\mathrm{H}$ and Ar were introduced into the system with a controlled flow rates of 10 and $90 \mathrm{cc} / \mathrm{min}$, resulting in approximately $10 \%$ of hydrogen gas mixture by mass. The gas mass flow was controlled using Alicat mass flow controllers. The gas mixture passed through alumina tube and discharged to a hydrogen ignitor. While continuous gas flow occurring, the chamber was heated with a rate of $10^{\circ} \mathrm{C} / \mathrm{min}$ until specimen temperature reached $500^{\circ} \mathrm{C}$. Once the maximum temperature was reached, specimens were soaked at $500^{\circ} \mathrm{C}$ for 2 to 4 hours, aiming hydrogen contents to lower than 300 wt. ppm. After hydriding process, the furnace was cooled to ambient temperature with its natural cooling rate. This procedure was selected from our previous experience with hydriding of cladding materials [12-14]. Due to the tight schedule of diffusion couple experiments, hydrided samples were not characterized, or hydrogen contents were not measured. The microstructural characterization was performed together with the diffusion couple microstructural characterizations ${ }^{\mathrm{a}}$.

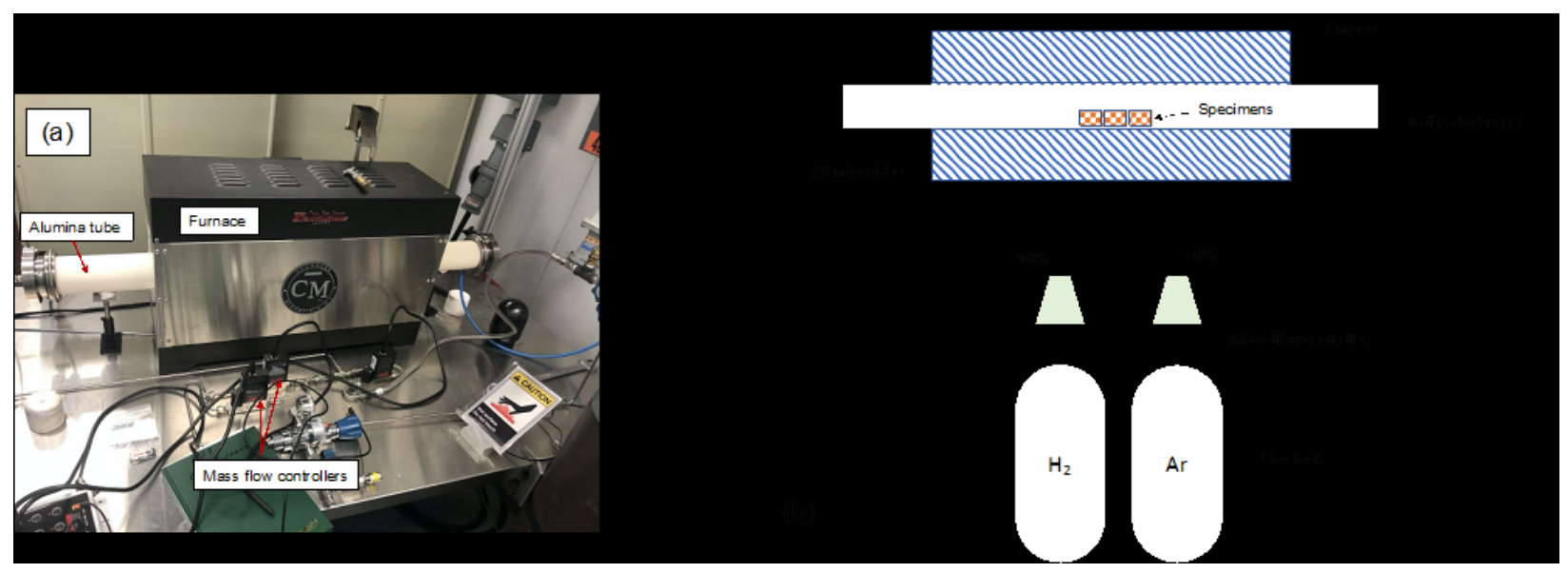

Figure 5. (a) Physical installation and (b) schematic of the hydriding system.

\subsubsection{Diffusion Couple Study}

\subsubsection{Diffusion couple preparation}

A typical diffusion couple setup is shown in Figure 6, where a Kovar alloy (nominal composition in wt.\%: Fe: balance, 29 wt.\% nickel (Ni), 17.0 wt.\% cobalt (Co), 0.3 wt.\% Mn, 0.2 wt.\% silicon (Si), \& 0.02 wt.\% carbon (C)) [15] was used as a diffusion couple jig. U-50Zr and Zircaloy-4 alloy (as received

\footnotetext{
${ }^{\text {a }}$ We acknowledge that a pre-characterization of hydrided Zircaloy-4 would be beneficial. For future activities, we will perform microstructure characterizations and hydrogen content measurements.
} 
and hydrided) were attached onto each other and inserted into the Kovar jig. To avoid any chemical interactions between samples and the jig material, Ta sheets were used for isolation as shown in Figure 6 . Samples were then bolt-tightened to $22.24 \mathrm{~N}$ (5lb) using a torque tool to improve contact surface between U-50Zr and Zry-4. The torque was directly applied to Ta sheet. After assembly, the diffusion couples were placed into a quartz ampoule. The quartz ampoule was purged with high-purity Ar gas and vacuum sealed at $1.410^{-5}$ mbar.

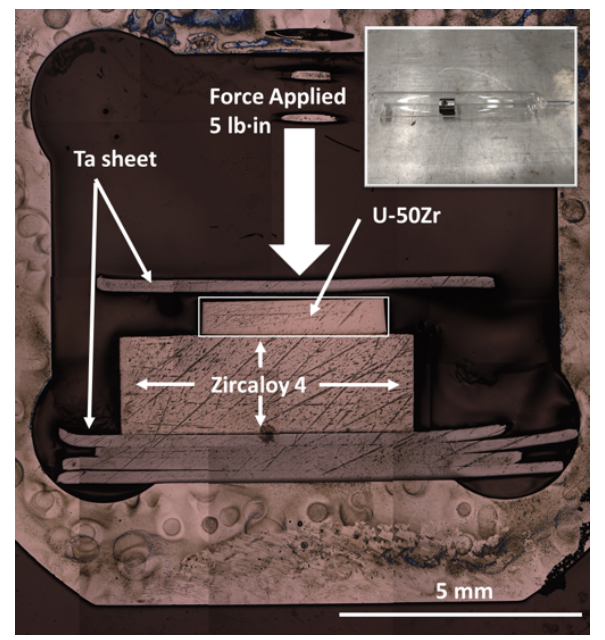

Figure 6. Experimental setup for the diffusion couple experiment. The diffusion couple jigs were sealed in a quartz ampoule as shown by inserted image - optical microscopy of the diffusion couple set up. U-50Zr is sandwiched by Ta sheets and Zircaloy-4 alloy; excessive amount of Ta sheets was used on the bottom to isolate reaction between Kovar jig and diffusion couple samples.

\subsubsection{Diffusion couple experiments}

The prepared diffusion couples (U-50Zr/Zry-4 and U-50Zr/hydrided-Zry-4) were subjected to isothermal high-temperature treatment at $375^{\circ} \mathrm{C}$ for $1,7,14$, and 24 days. The treatment temperature was selected to mimic LWR operating temperatures. Evolution of interaction layers of all diffusion couples were assessed using scanning electron microscopy (SEM) and transmission electron microscopy (TEM). Furthermore, one with assembled diffusion couple conditions was characterized using electron microscopy for comparison with other diffusion couples.

\subsubsection{Mechanical Testing}

Nanoindentation and indentation creep tests were performed using an Alemnis Standard Assembly indentation platform in a TESCAN LYRA3f SEM equipped with a focused-ion beam (FIB). The nanoindenter was equipped with a high-temperature module with independent temperature control of indenter and sample temperatures. Nanoindentation tests were performed using a spherical indent with a radius $(\mathrm{R})$ of $50 \mu \mathrm{m}$ to increase the number of grains in the deformed volume to mimic bulk material behavior as much as possible and to avoid complexity of testing a few grains. Nanoindentation measurements were performed under load control mode at 25,200 , and $375^{\circ} \mathrm{C}$. Indents were applied up to three maximum load levels of 100 and $200 \mathrm{mN}$ for each temperature. The loading and unloading rate were fixed at $5 \mathrm{mN} / \mathrm{S}$. Once reaching the peak load, a dwelling session up to 45 seconds was set up to stabilize the load before unloading. For high-temperature indents, the sample and the indenter were independently heated up to 200 and $375^{\circ} \mathrm{C}$ with a heating rate of $10^{\circ} \mathrm{C} / \mathrm{min}$. Once the targeted temperature reached, the indenter tip was moved closer to the sample surface for 30-60 minutes to achieve thermal equilibrium. After the stabilization session test indents were conducted to measure the thermal drift between the tip and the sample. If the drift was found to be excessive $(> \pm 0.15 \mathrm{~nm} / \mathrm{s})$, the sample temperature was adjusted and then another test indentation was performed. This was continued until the measured post-indentation thermal drift was less than $\pm 0.15 \mathrm{~nm} / \mathrm{s}$. 
The thermal drift was also evaluated during the unloading for the correction. Once the $90 \%$ of the maximum load was unloaded, the load was kept constant to evaluate the thermal drift effects. After indentation, load drift correction and displacement correction were performed using the Alemnis Materials Mechanics Data analyzer software. Then, the unloading portion of corrected displacement-load data was further analyzed to derive the hardness $(\mathrm{H})$ and elastic modulus $(\mathrm{E})$. A representative displacement (h)-loading (p) curve is shown in Figure 7.

For elastic constant determination, the Oliver-Pharr method was followed; the slope of the initial portion of the unloading curve $(\mathrm{dP} / \mathrm{dh})$ was used to determine depth of the contact $\left(\mathrm{h}_{\mathrm{a}}\right)$ as shown in Equation 1

The plastic depth $\left(h_{p}\right)$ was then estimated using, where $h_{t}$ was the total impression depth at the maximum load $\left(\mathrm{P}_{\max }\right)$, and the contact area $(\mathrm{A})$ was determined using. The combined elastic modulus (E') of indenter tip and the sample was determined using

Once the elastic contribution from the spherical indent was removed, the elastic modulus of the specimen $\left(\mathrm{E}^{*}\right)$ was determined using the relationship between the reduced modulus and the elastic properties (E: elastic modulus, v: Poisson's ratio) written as . The hardness value $(H)$ was determined using .

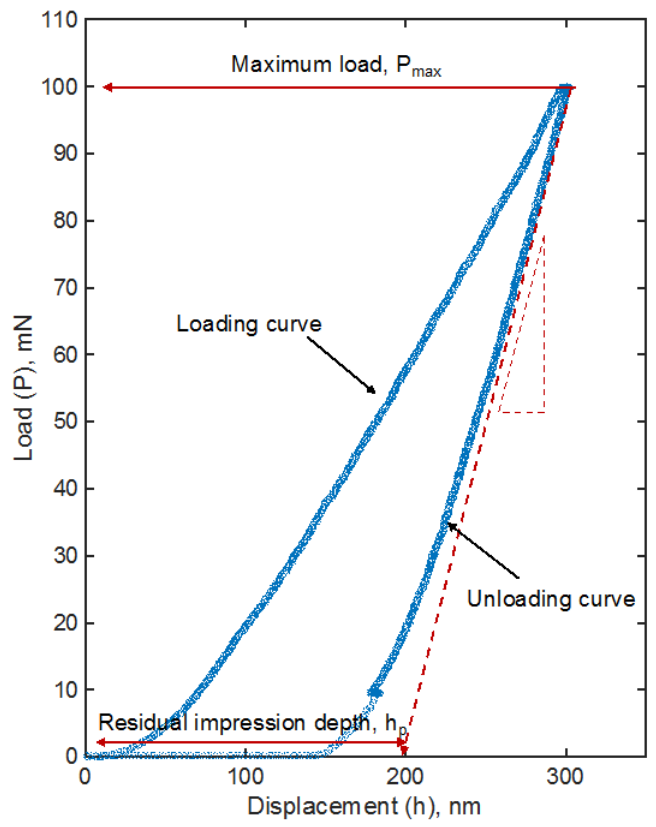

Figure 7. Typical nanoindentation load displacement curve of U-50Zr where the maximum load was 100 $\mathrm{mN}$ at room temperature. The radius of the indenter was $50 \mu \mathrm{m}$.

Expanding cavity model (ECM) for the spherical indenter $[16,17]$ was used for the apparent yield stress $\left(\sigma_{\mathrm{y}}\right)$ determination to determine the lower limit of the yield stress. ECM assumed that the material was elastic and perfectly plastic (no strain hardening) and the relation between yield stress, elastic modulus $€$, hardness $(\mathrm{H})$, and the contact radius(a) was given as follows 
The above equation was solved iteratively until $\sigma_{\mathrm{y}}$ converged to a constant value using $\mathrm{H}$ and $\mathrm{E}$ values for each temperature. The ECM yield stress was also compared with the constraint factor (CF) calculated yield stress using

Constant load nanoindentation creep tests were performed using spherical tips with $\mathrm{R}=20$ and $50 \mu \mathrm{m}$. With the $20-\mu \mathrm{m}$ indenter, the creep tests were conducted with a peak load of $100 \mathrm{mN}$ at three temperatures, 25,200 , and $375^{\circ} \mathrm{C}$. Due to tight instrument time, limited creep tests have been performed with 50-um indenter. The specimen was impressed with the indenter tip until peak load was reached, and the load was kept constant for $300 \mathrm{~s}$ at the peak load to let specimen creep. After dwelling, the specimen was unloaded as shown in Figure 8.

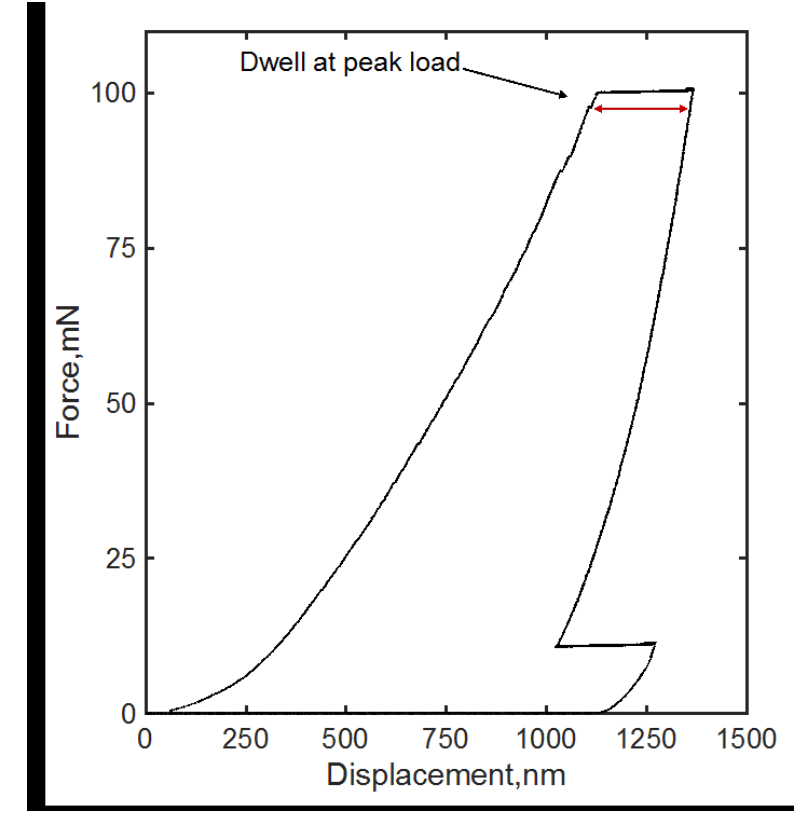

Figure 8. Typical nanoindentation creep force displacement curve of U-50Zr at $200^{\circ} \mathrm{C}$. Specimen was held at constant load of $100 \mathrm{mN}$. The radius of the indenter was $50 \mu \mathrm{m}$.

The nanoindentation creep data analysis assumed that the material obeys power law creep behavior where the relation between stress and creep rate () is given for uniaxial tension conditions

where A is a pre-factor which depends on temperature. Bower et al. [18] related the pressure under the indent (P) based on Mulhearn and Tabor's approach [19] as follows

where $\mathrm{a}$ is the contact radius of the indenter, $\alpha$ and $\gamma$ are the material constants, $\sigma_{\mathrm{o}}$ is the corresponding uniaxial creep stress, is the effective creep rate for the indentation test, and is the corresponding uniaxial creep rate.

This study analyzed the thermal creep using Choi et al. [20] and Lee et al.'s [21] approaches for the spherical indenters. The creep displacement was estimated using

where $h$ is the indenter displacement and $h_{i}$ the indenter displacement at the onset of creep. The creep strain was then calculated using the contact radius (a) and indenter radius (R) as follows 
The experimentally determined creep strain was then fitted to an empirically developed Garofalo's Equation $9^{22}$

where $\alpha, r$, and $\omega$ are fitting parameters. Here, we note that nanoindentation creep data analysis has multiple approaches in the literature [19,22]. This topic is still under active research. Accuracy of the results presented in the report can be improved by applying inverse techniques. Results provide audience preliminary understanding on the creep behavior of U-50Zr.

\subsubsection{X-ray Diffraction and Electron Microscopy}

Fabricated U-50Zr fuel was characterized using XRD, SEM, and TEM. For XRD characterization, a PANalytical ${ }^{\circledR}$ AERIS compact XRD diffractometer was used to study the phase inside casted fuel sample. Polished samples were mounted on a holder that have height correction for XRD measurement. Data was collected in the range of 20-100 degrees $2 \theta$ with a step size of 0.02 degrees.

As-fabricated microstructure of the U-50Zr was characterized using SEM (JOEL $®$ IT500HR) equipped with an electron back-scattering diffraction (EBSD) detector. All EBSD measurement were performed on polished sample with 70 degree tilting angle at a beam current of $54 \mathrm{nA}$ toward detector. A $0.1 \mu \mathrm{m}$ step size was used for data collection.

Analytical TEM was performed on diffusion couple samples and mechanically tested samples. TEM specimens were first prepared using FIB milling on a Thermo Scientific Quanta 3D dual-beam FIB in irradiated materials characterization laboratory (IMCL) in MFC of INL. Lift-out of materials with dimensions of $10 \times 10 \times 1 \mu \mathrm{m}$ were extracted and mounted to copper TEM grids. The lift-outs were subsequently thinned to $<100 \mathrm{~nm}$ for TEM observation. Ga ion beams of various energy and current were used for thinning. Final thinning was done using a $5 \mathrm{keV}$ and $48 \mathrm{pA}$ to locally perforate the sample followed by a final polishing using a Ga ion beam of $2 \mathrm{keV}$ and $27 \mathrm{pA}$. TEM samples were prepared on the diffusion couples at the Zircaloy-4 and fuel interface using a FIB. The FIB samples are $1010 \mu \mathrm{m}$ in size and with a thickness $\sim 100 \mathrm{~nm}$. To avoid oxidation, the sample was unloaded from FIB, surveyed, and quickly loaded into the FEI Titan TEM equipped with a field-emission gun operated at $200 \mathrm{kV}$. Scanning TEM (STEM) and Energy dispersive x-ray spectroscopy (EDS) was collected using a Super-X EDS System based on ChemiSTEM technology. The STEM-EDS data was collected from an energy range from 0 to $40 \mathrm{keV}$. Phase identification was primarily carried out based on the indexing of selectedarea diffraction patterns (SAED).

\subsubsection{Thermophysical property characterization}

Bulk thermal diffusivity $\left(\mathrm{mm}^{2} / \mathrm{s}\right)$ was measured using a Netzsch laser flash analyzer (LFA427) instrument. A Pyroceram 9600 standard was used to verify the calibration of the instrument and its detectors. Thermal diffusivity data was collected from 25 to $800^{\circ} \mathrm{C}$ and back down to room temperature. The heating and cooling rates between shot temperatures were varied between $1{ }^{\circ} \mathrm{C} / \mathrm{min}$ and $10^{\circ} \mathrm{C} / \mathrm{min}$. Ultra-high purity (UHP) argon was used as the cover gas at a flow rate of $150 \mathrm{~mL} / \mathrm{min}$. Differential Scanning Calorimetry (DSC) was performed using a Netzsch DSC 404F1 instrument. The samples were placed in yttria-lined platinum - rhodium (Pt-Rh) crucibles. The DSC signal was measured upon heating and cooling at a rate of $10^{\circ} \mathrm{C} /$ minute. Ultra-high purity argon (UHP Ar) was used as the cover gas at a flow rate of $20 \mathrm{~mL} / \mathrm{min}$ after passing it through an Oxy-gon OG-120M oxygen gettering furnace.

Linear thermal expansion was measured via dilatometry using a Netzsch DIL 402E pushrod dilatometer. UHP Ar was used as the cover gas at a flow rate of $100 \mathrm{~mL} / \mathrm{min}$. The samples were place on an alumina holder with a hemi-cylindrical groove. The instrument was calibrated using a $12.00 \mathrm{~mm}$ sapphire standard. Data produced by the dilatometer and DSC and were analyzed using Netzsch Proteus Thermal 
Analysis Software version 6.1. All sample dimensions and weights were measured using vernier calipers and an analytical balance, respectively. The room temperature density of the as-cast U-50Zr samples was measured with a value of $9.55 \mathrm{~g} \mathrm{~cm}^{-3}$.

\section{RESULTS AND DISCUSSION \\ 4.1 Microstructure of the As-fabricated U-50Zr}

The microstructure of the cross section of an as-fabricated fuel pin included elongated grains along the radial direction from fuel pin center to rim (highlighted by white arrow), which was the solidification direction when the hot melt met the cold casting mold. These columnar grains are $500 \mu \mathrm{m}$ wide and $\sim 2000 \mu \mathrm{m}$ long. It appears the large columnar grains formed during solidification. High-magnification SEM images indicate there are sub-domains inside the parent grains. While the grain boundaries were decorated by the alpha-zirconium precipitates, intragranular acicular-zirconium precipitates were also observed.

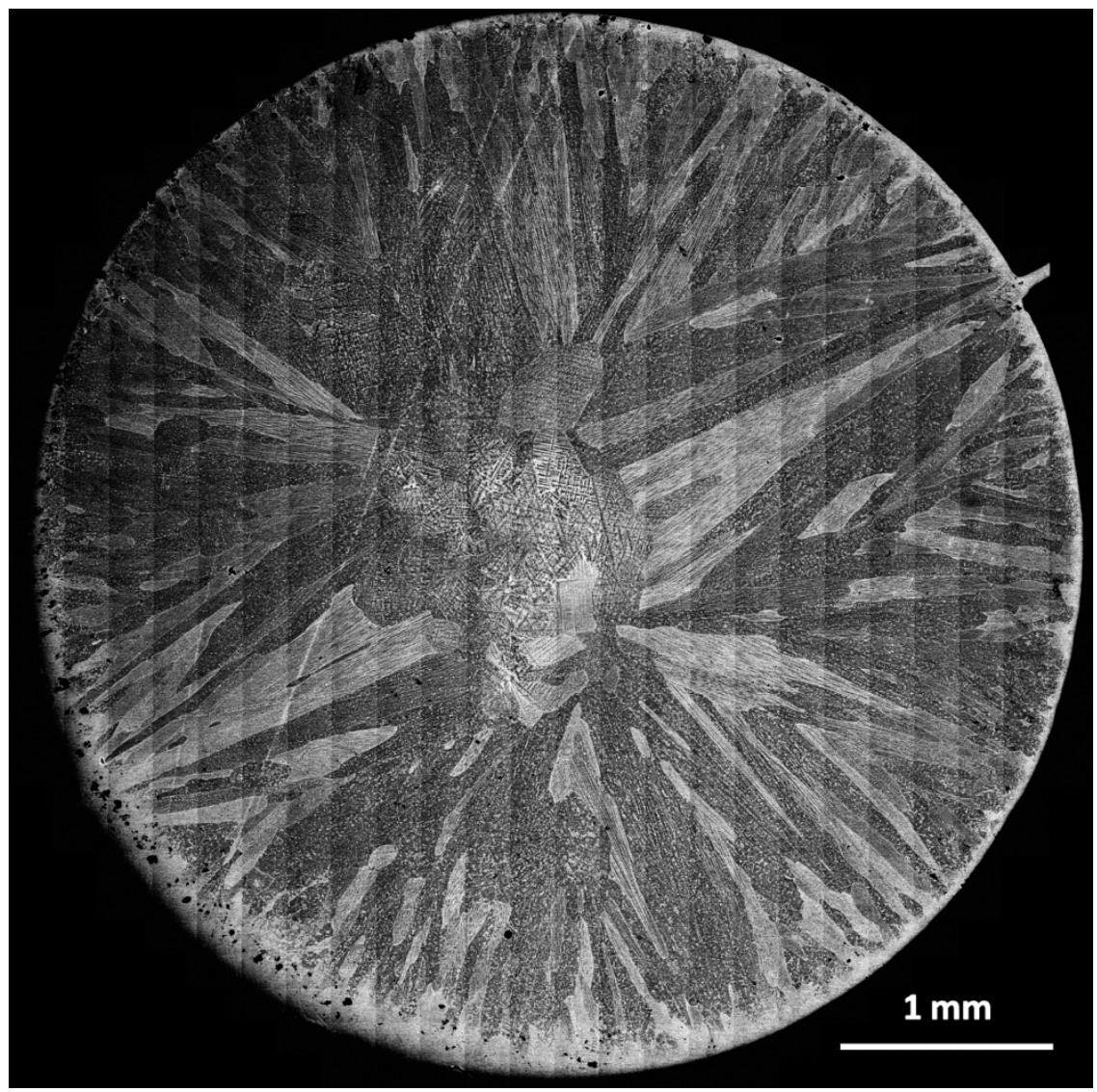

Figure 9. SEM image of the as-fabricated fuel, showing features for casted microstructure with columnar grains.

XRD peak indexing (Figure 10) indicated the dominant phase is the hexagonal $\delta-\mathrm{UZr}_{2}$. Peaks were sharp and fitted well with the ideal peak positions of $\delta-\mathrm{UZr}_{2}$. Peaks for the minor phase, such as those around 32.0 degree and 63.5 degree, were broad and of low intensity. These peaks were attributed to $\alpha-\mathrm{Zr}$ which is also hexagonal closed packed structure. The peaks for $\alpha-\mathrm{Zr}$ were slightly shifted due to the compression from the parent $\mathrm{U}-50 \mathrm{Zr}$ phase. 
EBSD revealed the phase distribution and its crystallographic orientation simultaneously for localized grains. Each columnar grain consisted of sub-grains. These sub-grains inside each columnar grain seem to show two orientations with misorientation angle concentrated around 65 degrees. This angle might be related to the orientation of $\omega$-variant formed during the phase transformation from high-temperature body-centered cubic (bcc) to low-temperature hexagonal crystal structure. Some of the columnar grains did not have usable patterns to index.

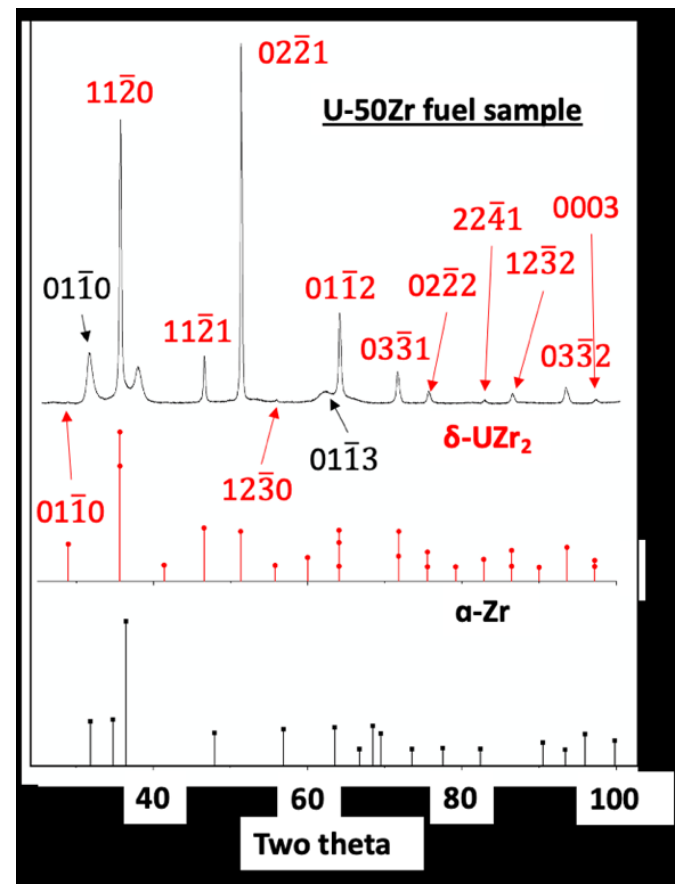

Figure 10. XRD spectrum and indexing against theoretical peak positions for $\delta$-UZr2 and $\alpha-Z r$.

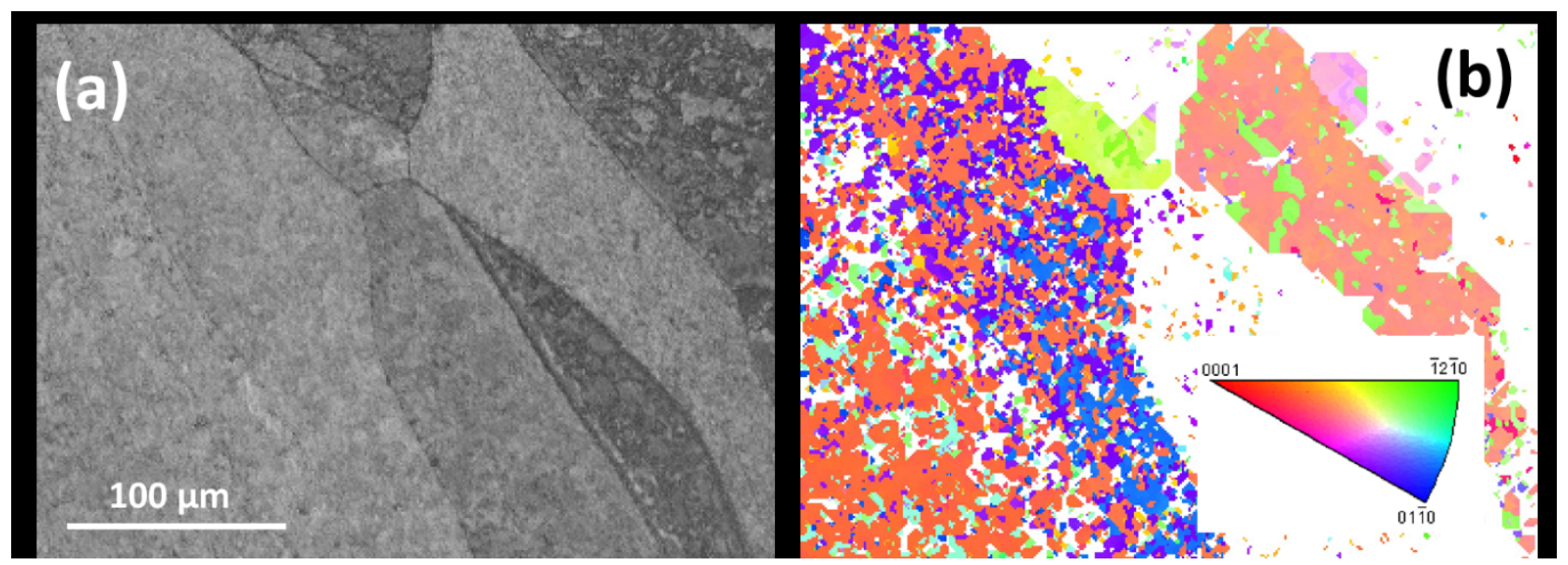

Figure 11. Forward scattered electron image (a) of the area where electron backscattered electron diffraction patterns were collected and analyzed to produce the orientation mapping of hexagonal $\mathrm{UZr}_{2}$ phase (b). Inside each parent bcc grain, there are two dominant orientations for the hexagonal phase. Some grains do not have patterns recognizable for hexagonal $\mathrm{UZr}_{2}$ phase.

\subsection{Nanoindentation Tests}

Figure 12 shows a typical array of indentation marks on the specimen surface. The microstructure of the specimen included elongated grains which consisted of equiaxed sub-grains of U-50Zr. Note surface 
cracking was observed between these sub-grain boundaries in the parent U-50Zr grains due to the specimen polishing.

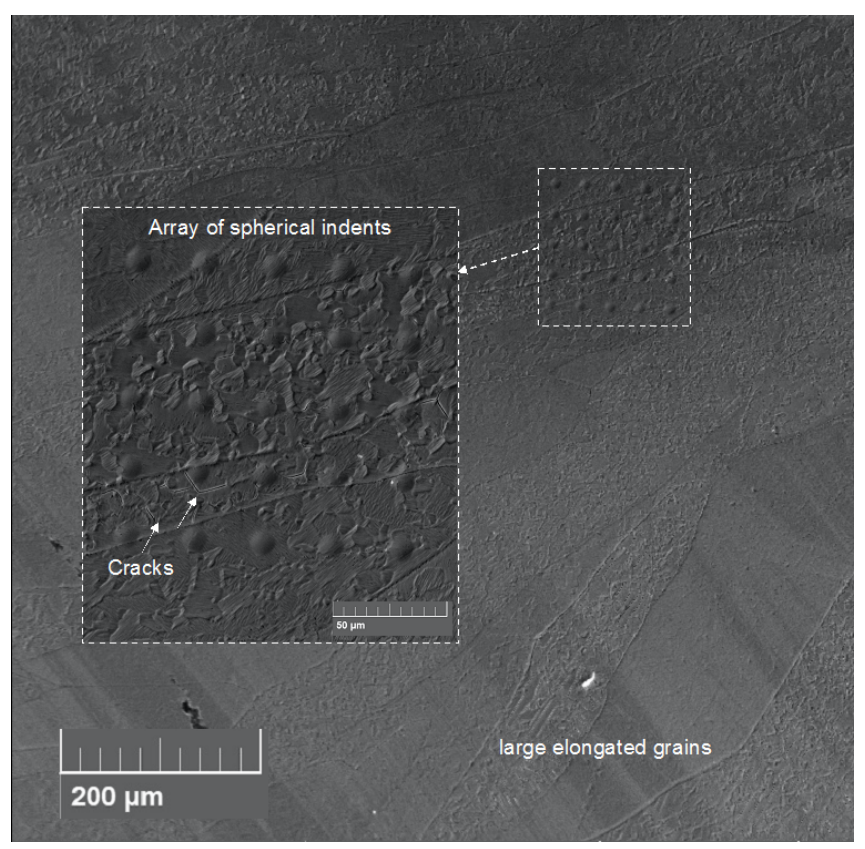

Figure 12. Spherical indents in U-50Zr microstructure.

Table 2 lists the average hardness and elastic modulus values of the U-50Zr as determined via nanoindentation and compares indentation results with the literature values. Hardness decreased from 1.55 to $1.08 \mathrm{GPa}$, a $30 \%$ reduction, as the temperature increased from 25 to $375^{\circ} \mathrm{C}$ (see Figure $13 \mathrm{a}$ ). Because hardness is an indicator for the yield strength, a $30 \%$ decrease in the yield value was expected assuming the linear relationship between hardness and the yield stress via the $C F\left(C \sim H / \sigma_{y}\right)$. Rather, the elastic modulus showed no appreciable change as a function of temperature. Changes were within the one-standard $(1-\sigma)$ deviation. Except room temperature data, elastic modulus was consistent with the ultrasound measurements performed by Khanolkar et al. [23]. The difference might be related to the local microstructural changes on the specimen surface and probing limited number of grains would affect the values due to the anisotropy.

Table 2. Temperature-dependent average hardness and elastic modulus of $\mathrm{U}-50 \mathrm{Zr}$ via nanoindentation.

\begin{tabular}{|l|l|l|l|}
\hline Temperature, ${ }^{\circ} \mathrm{C}$ & Hardness, GPa & Elastic modulus (E), GPa & E from Khanolkar et al., GPa \\
\hline 25 & $1.55 \pm 0.33$ & $98.01 \pm 6.26$ & $\sim 121$ \\
\hline 200 & $1.32 \pm 0.29$ & $113.08 \pm 13.61$ & 117 \\
\hline 375 & $1.08 \pm 0.25$ & $100.94 \pm 18.52$ & $\sim 110$ \\
\hline
\end{tabular}




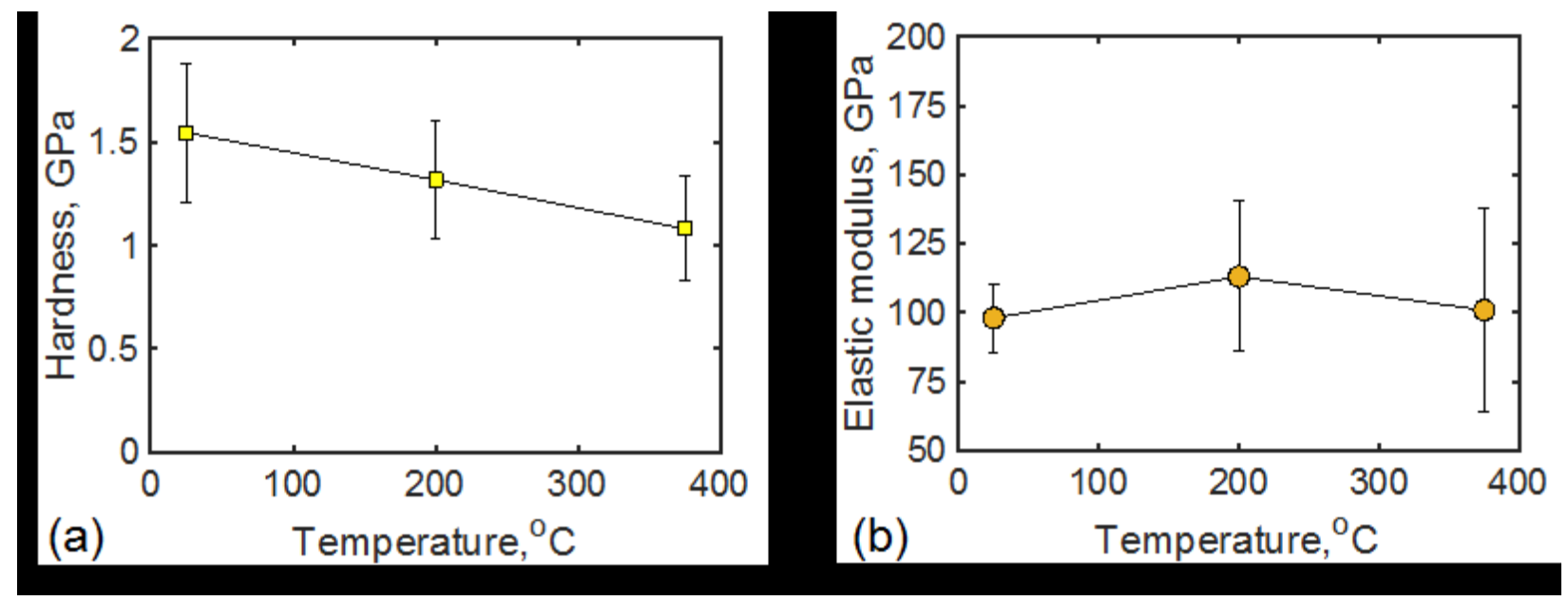

Figure 13. (a) Temperature-dependent hardness and (b) elastic modulus of U-50Zr.

Figure 14 shows a typical iterative solution of Equation 3 for initial yield stress estimates of 100, 500, $2000 \mathrm{MPa}$ to depict the convergence of the ECM equation for elastic and perfectly plastic material model. Independent of the initial yield stress guess, the calculated yield stress converged to the same final value, which indicated the ECM model was working.

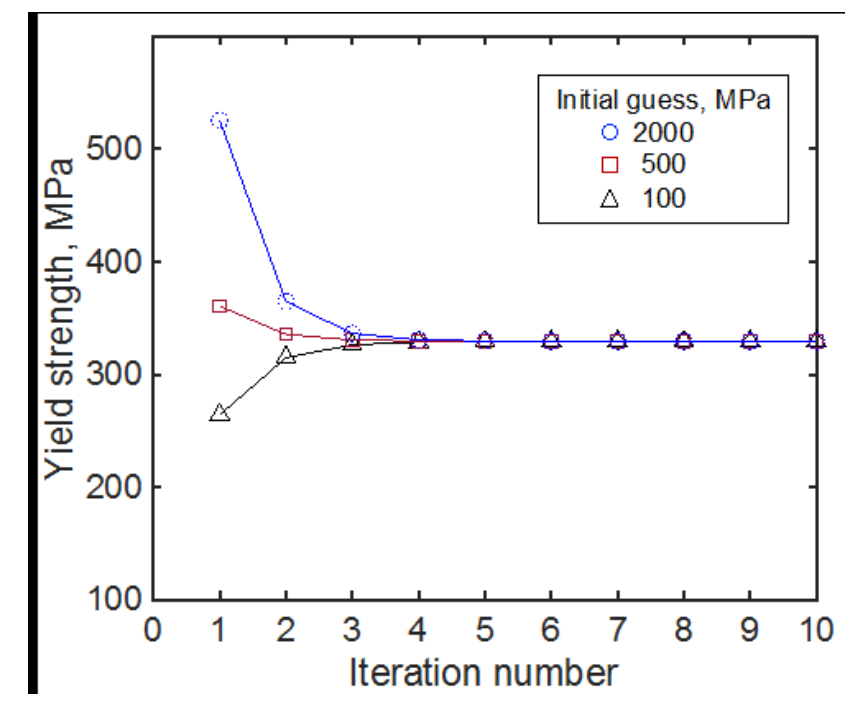

Figure 14. Yield stress predictions using ECM model with different initial yield stress guesses.

Table 3 lists both ECM- and CF-estimated yield strengths as a function of temperature, and Figure 15 shows the temperature dependency of the ECM-calculated yield stress. The ECM model was for perfectly elastic material condition while CF represented the full plastic yielding condition for the material. It should be considered that the actual yield strength was expected to be between ECM- and CF-calculated values. Rough reported yield stresses as 549.5 and $466 \mathrm{MPa}$ at room temperature and $200^{\circ} \mathrm{C}$, respectively, for rolled and annealed U-50Zr fuel [24] (this is the only known data available on the yield stress). Since the fuel was rolled and annealed, the yield stress was expected higher than the yield stress of the arcmelted U-50Zr due to work-hardening effects. The fuel used in this study was an as-fabricated condition where large grains (with sub-grains) were present, and the yield stress was also expected to be significantly lower than that of the rolled and annealed material reported by Rough [25].

Thus, our expectation is the yield stress is close to the ECM value rather than CF value. However, more detailed data analysis and tensile testing is suggested. 
Table 3. ECM- and CF-calculated yield strengths of U-50Zr.

\begin{tabular}{|l|l|l|}
\hline Temperature, ${ }^{\circ} \mathrm{C}$ & ECM-, MPa & CF $(\sim 3), \mathrm{MPa}$ \\
\hline 25 & 329.0 & 516.7 \\
\hline 200 & 300.8 & 440.0 \\
\hline 375 & 292.9 & 360.0 \\
\hline
\end{tabular}

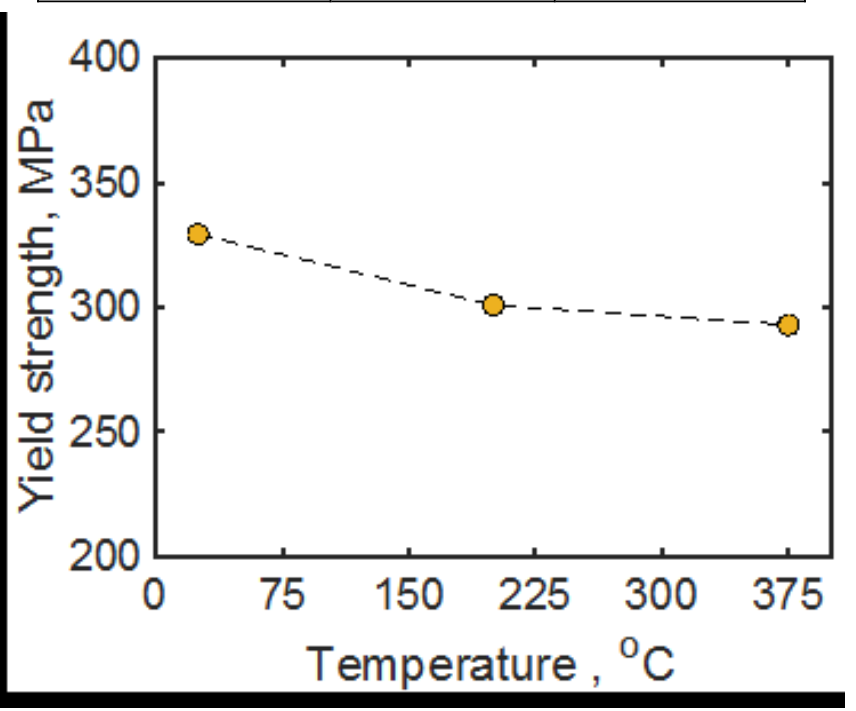

Figure 15. Temperature-dependent ECM-estimated yield stress of U-50Zr.

Figure 16 shows the creep strain of the specimen tested at $200^{\circ} \mathrm{C}$ under a constant load of $100 \mathrm{mN}$. The creep strain was determined via Equation 8, and the data was fitted using Equation 9. The creep rate was determined by taking the derivative of the Equation 9 at the maximum told time. Results of the fitting parameters were listed in the Table 3 as well as the creep rate. The assessment of the data was stopped at this step since more experimental data was needed at different applied load levels to determine the creep parameters such as creep exponent $(1 / \mathrm{m})$ and creep coefficient $(\mathrm{A})$. The creep rates were determined in the order of $10^{-4}$ and $10^{-5}$. These high-creep rates might be caused by larger grain sizes and multiaxial stress state under the indent. Furthermore, the applied load might cause initial plastic deformation followed by thermal creep. 


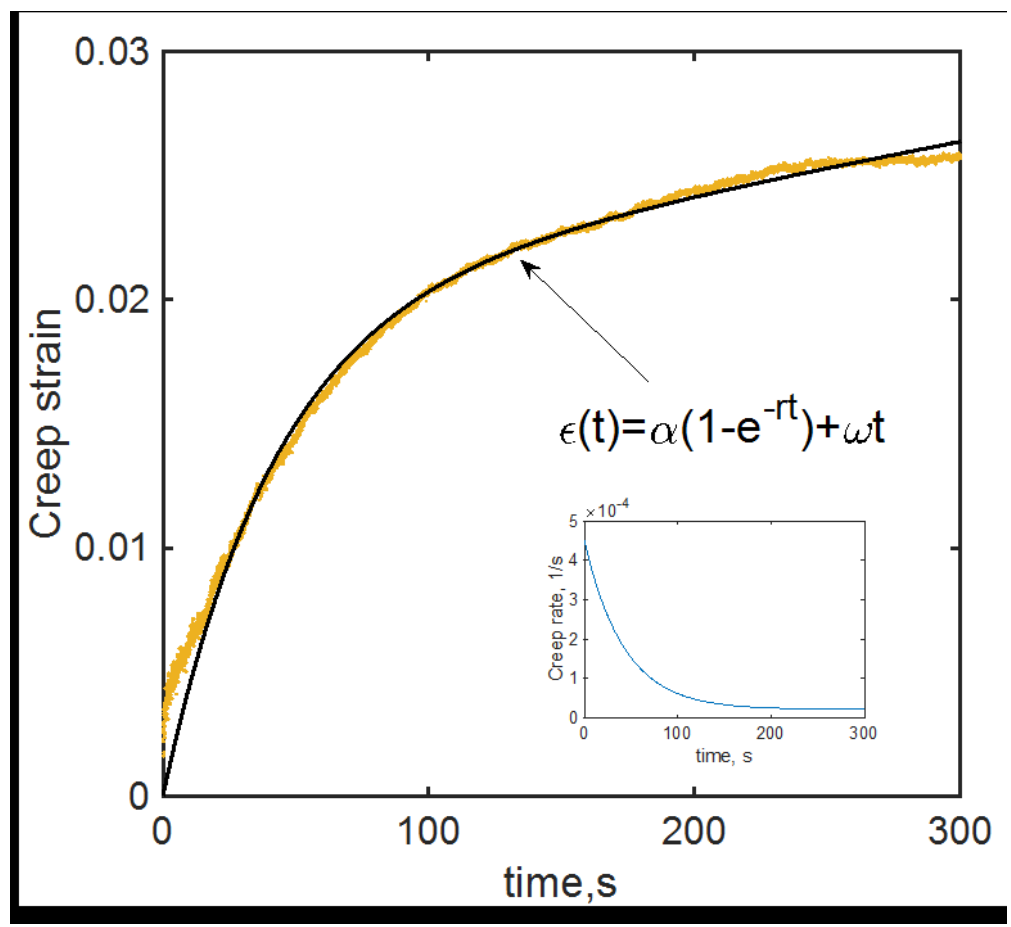

Figure 16. Indentation creep strain and creep rate at $200^{\circ} \mathrm{C}$, indenter radius: $50 \mu \mathrm{m}, \mathrm{P}_{\max }=100 \mathrm{mN}$.

Table 4. Creep-curve fit results for various experiments.

\begin{tabular}{|l|l|l|l|l|l|l|}
\hline $\mathrm{R}, \mu \mathrm{m}$ & $\mathrm{T},{ }^{\circ} \mathrm{C}$ & $\mathrm{P}_{\max }, \mathrm{mN}$ & $\alpha$ & $\mathrm{r}$ & $\omega$ & $\partial \epsilon / \partial \mathrm{t}$ \\
\hline 50 & 200 & 100 & 0.02014 & 0.02362 & $2.081 \mathrm{e}-5$ & $2.118 \mathrm{e}-5$ \\
\hline 50 & 200 & 100 & 0.02702 & 0.0172 & $-5.688 \mathrm{e}-6$ & $2.137 \mathrm{e}-5$ \\
\hline 50 & 200 & 200 & 0.02727 & 0.01784 & $-3.291 \mathrm{e}-5$ & $2.179 \mathrm{e}-5$ \\
\hline 20 & 200 & 100 & 0.0357 & 0.06265 & $5.851 \mathrm{e}-5$ & $5.94 \mathrm{e}-5$ \\
\hline 20 & 375 & 100 & 0.03026 & 0.1521 & $66.517 \mathrm{e}-4$ & $5.85 \mathrm{e}-5$ \\
\hline 20 & 375 & 100 & 0.04806 & 0.04086 & $1.503 \mathrm{e}-4$ & $1.503 \mathrm{e}-4$ \\
\hline 20 & 375 & 100 & 0.0263 & 0.09426 & $1.192 \mathrm{e}-4$ & $1.192 \mathrm{e}-4$ \\
\hline 20 & 375 & 100 & 0.01642 & 1.393 & $1.573 \mathrm{e}-4$ & $1.573 \mathrm{e}-4$ \\
\hline
\end{tabular}

The crept microstructure beneath the indenter mark was characterized using analytical TEM as shown in Figure 17. Observed important features (i) were dislocation sub-structuring as a result of thermal creep deformation. The sub-structuring consisted of multiple dislocations stacked onto each other and oriented with respect the zirconium precipitates at the grain boundary. This structure confirmed that the creep behavior was governed by power law for U-50Zr. Furthermore, heavily twinned regions were observed in the grain (ii). In between these twins, the dislocation sub-structuring was also observed. This indicated that the twinning was dominant during the continuous loading regime prior to the constant loading regime of the creep test. 


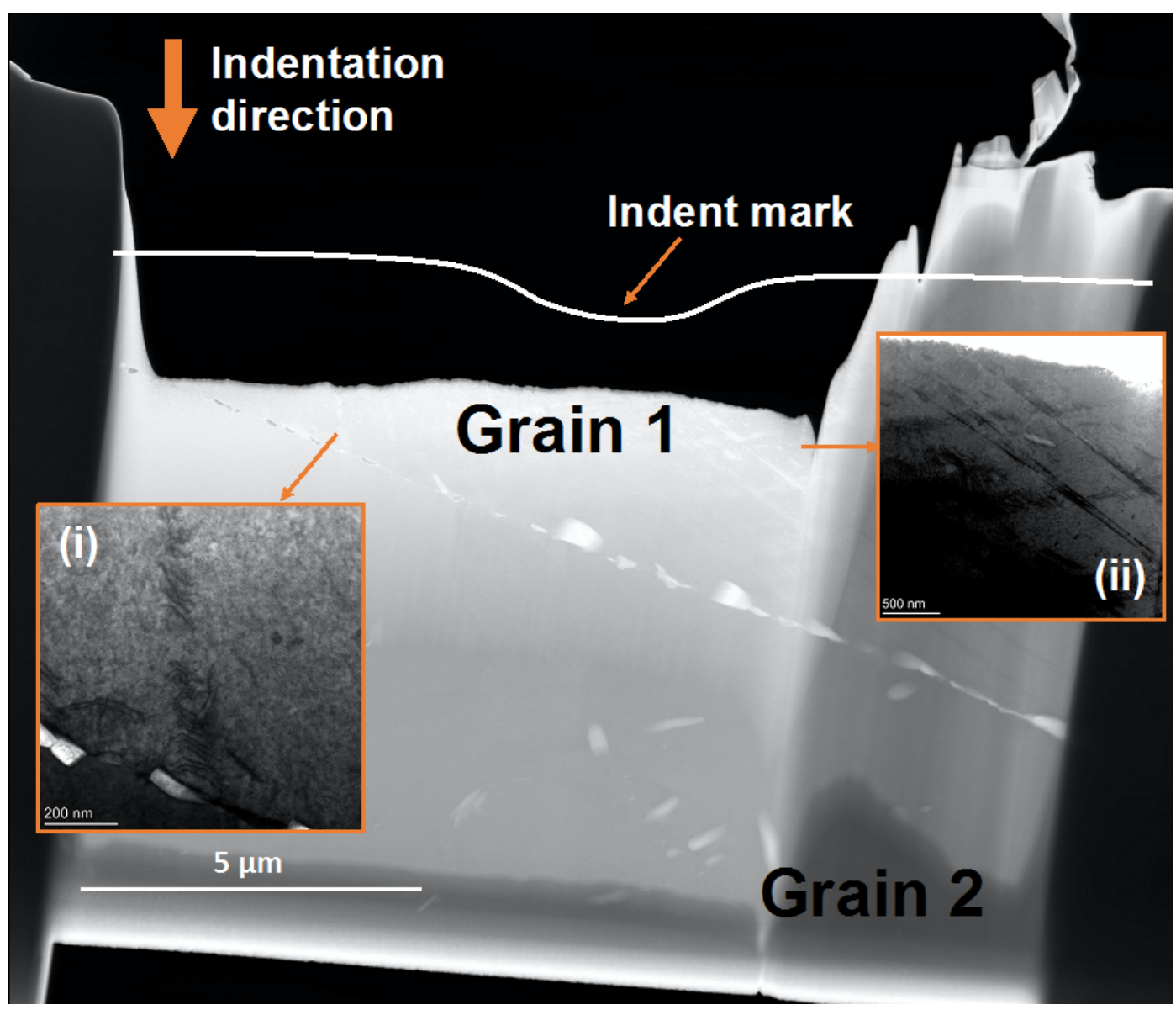

Figure 17. Analytical transmission electron micrograph of U-50Zr showing the microstructure beneath the indenter (i) shows the creep-induced dislocation sub-structuring with respect to a zirconium precipitate, (ii) shows twinned regions and the dislocation.

\subsection{Diffusion Couple Characterizations}

SEM characterization of diffusion couple interface, Figure 18, revealed little chemical interaction between U-50Zr and Zircaloy-4 alloy, even for the sample hold at $375^{\circ} \mathrm{C}$ for 28 days. The interaction was beyond the resolution of SEM (see Figure 18), and, therefore, we prepared two TEM samples from the 7 and 28 days diffusion couples.

Because the LWR fuel cladding can form hydrides, we also investigated the effect of the hydrogen on diffusion of species. The SEM (Figure 19) showed the presence of hydrides (see orange arrows in Figure 19) and formation of an appreciable interaction layer after 14 days hold at $375{ }^{\circ} \mathrm{C}$ for the diffusion couple between U-50Zr and hydrided-Zircaloy cladding. EDS characterization indicated no observable intermixing of $U$ and $Z r$. The layer had a thickness around $200 \mathrm{~nm}$. This shallow interaction layer makes SEM-EDS analysis challenging to distinguish $U$ and $\mathrm{Zr}$-rich regions due to the large interaction volume from SEM electron beam (close to $1 \mu \mathrm{m}$ ). However, the differences between non-hydrided and hydrided diffusion couple were evident. This phenomenon requires investigation in more detail using TEM. If possible, the cladding materials should be replaced with modern $\mathrm{Zr}-\mathrm{Nb}$ cladding materials. 


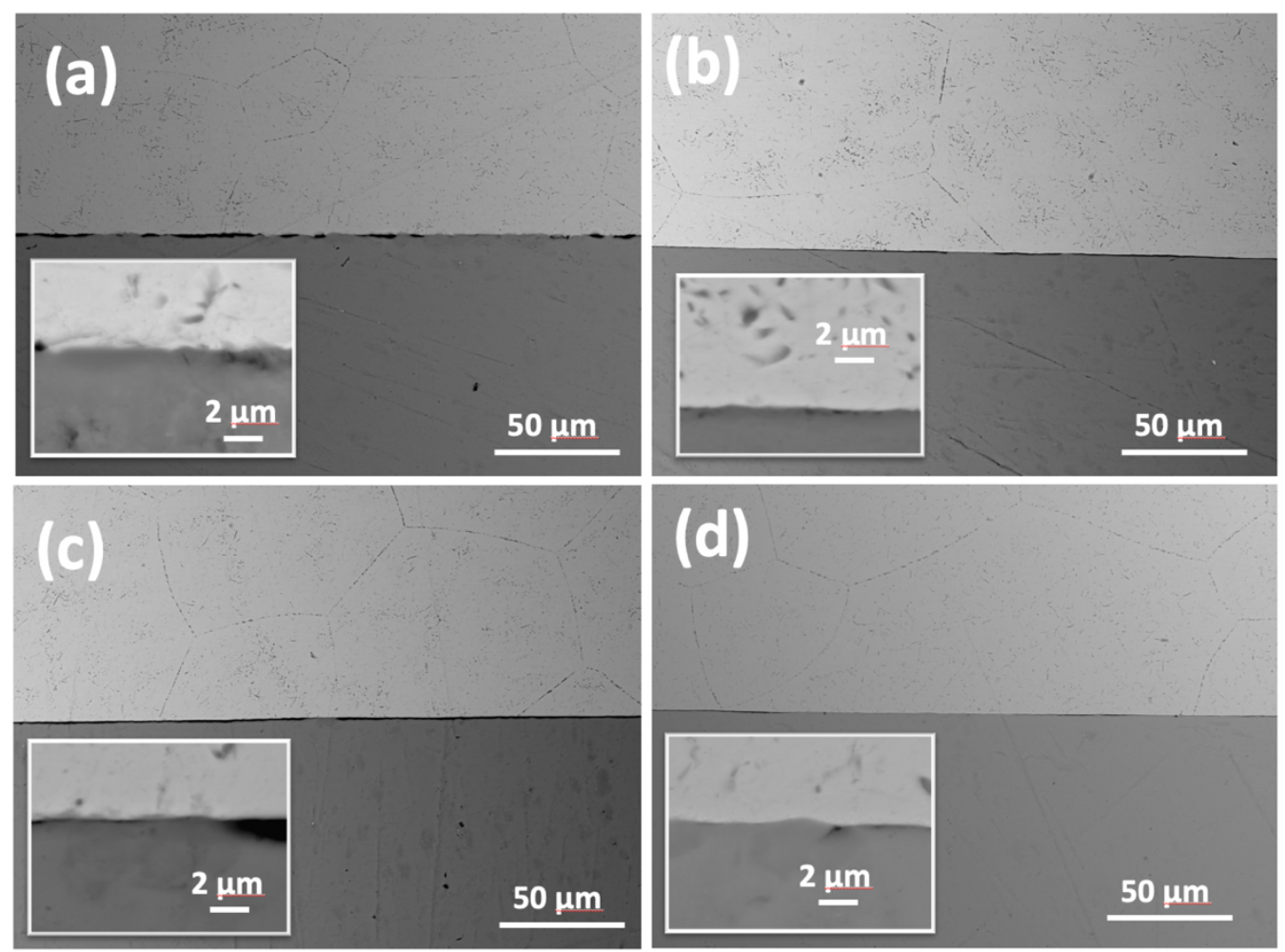

Figure 18. SEM images of the interaction between U-50Zr and Zircaloy-4 sample after various days hold at $375^{\circ} \mathrm{C}$ for 0 days (a); 1 day (b), 7 days (c), and 28 days (d) with higher magnification SEM images of the interface region inserted at bottom left corner. Gaps between the Zr-4 and the U-50Zr are explained by thermal expansion and contraction after heating and cooling of the diffusion couples.

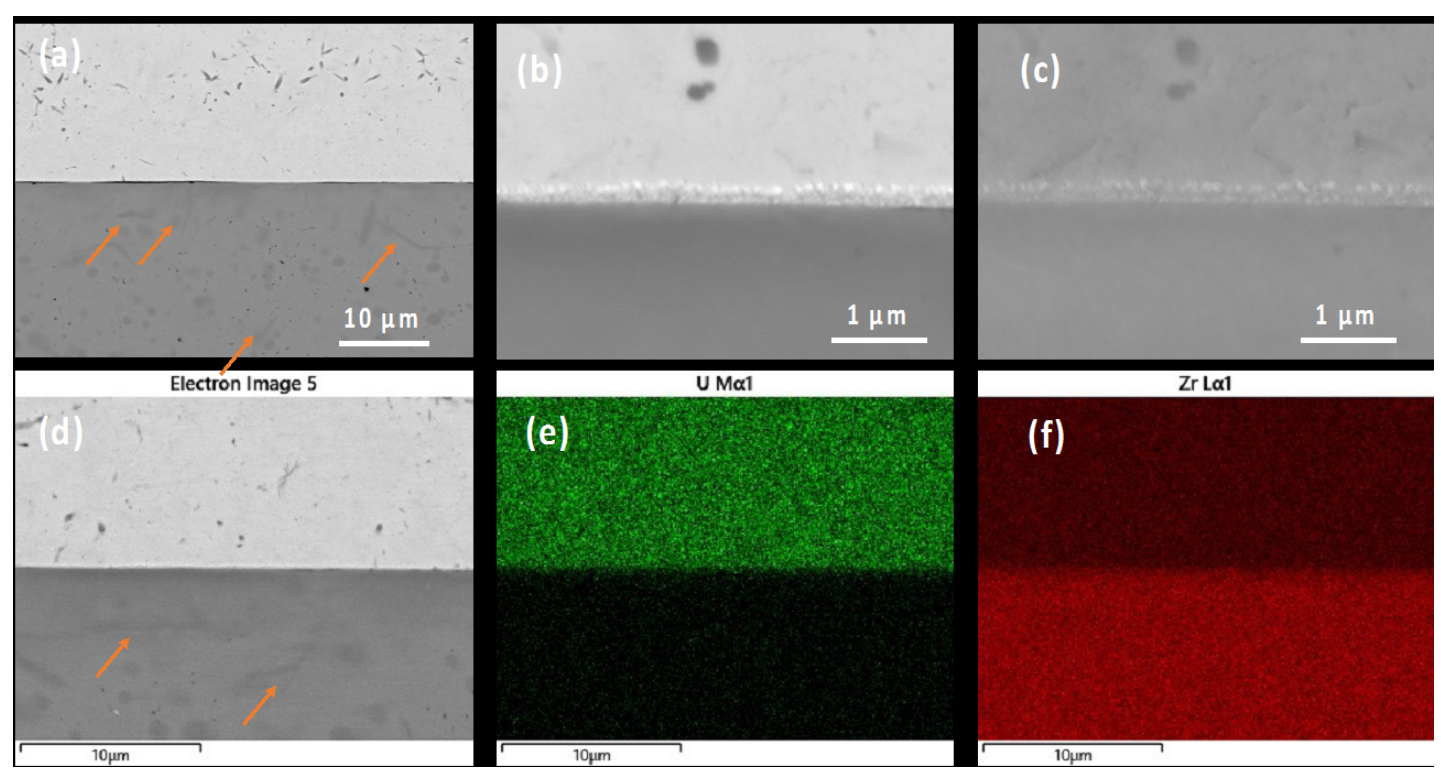

Figure 19. SEM images of the interaction between U-50Zr and hydrided Zircaloy-4 sample after 14 days hold at $375^{\circ} \mathrm{C}$, showing the formation of a $200 \mathrm{~nm}$ thick layer of interaction with possible U-rich band at the interface $(\mathrm{a}-\mathrm{d})$. However, SEM-EDS could not resolve the chemical variation across the interaction (e-f). Orange arrows indicates hydrides in the Zircaloy- 4. 
Figure 20 is an overview of the TEM sample prepared from 7-day diffusion couple sample as well as electron diffraction patterns for Zircaloy-4 and U-50Zr side. The phases were indexed to be expected $\alpha-Z r$ for the Zircaloy-4 side and hexagonal $\mathrm{UZr}_{2}$ phase for $\mathrm{U}-50 \mathrm{Zr}$ side. The precipitates in the U-50Zr, also shown in Figure 17 and Figure 18, were $\alpha-Z r$ in hexagonal crystal structure. The formation of these precipitates were attributed to the solubility limit of $\mathrm{Zr}$ in hyper-stoichiometric $\mathrm{UZr}_{2.6}$ during post-casting annealing at $550^{\circ} \mathrm{C}$. The wide gap, now being filled by epoxy should formed during cooling due to the different thermal shrinking rate between U-50Zr and Zircaloy-4 alloy. The diffusion interaction layer was sub-micron and not strong enough to hold the diffusion couple together.

The 28-day TEM sample shows an appreciable interaction (Figure 21). The interaction regions are divided into four layers by the morphology of secondary phase and chemical concertation. The first layer of interaction is a nanocrystalline $\left(\mathrm{Zr}_{0.7} \mathrm{U}_{0.25} \mathrm{Sn}_{0.03} \mathrm{Cr}_{0.02}\right) \mathrm{O}_{2}$ layer. The source of oxygen was mainly from Zircaloy-4 or could be the residual oxygen in the sealed quartz ampoule. However, the thickness was limited to $500 \mathrm{~nm}$. Moving into the U-50Zr fuel, U nanoparticles were dominant phase in a Zr-rich matrix. Apparently, U nanoparticles were originated from phase decomposition from $\mathrm{UZr}_{2.6}$. The third layer is featured by columnar $\alpha$-U grains penetrated towards to the diffusion couple interface. The fourth layer was the grain subdivision of U-50Zr matrix and precipitation of $\alpha-U$ on grain boundary and triple junctions. The subdivided grains crystalize in same structure with $\mathrm{UZr}_{2.6}$.

The chemical element mapping of $\mathrm{U}, \mathrm{Zr}, \mathrm{Fe}, \mathrm{Cr}, \mathrm{Sn}, \mathrm{Si}$, and $\mathrm{O}$ is shown in Figure 22. The information was complementary to the analysis provide in above paragraph. The interaction layer was lacking major alloying elements of Zircaloy-4 alloy, including Fe, $\mathrm{Cr}$, and $\mathrm{Sn}$. $\mathrm{Zr}$ and Fe were complementary to each other at the interaction region. A comparison of sample from 7 days and 28 days is shown in Figure 23. The interaction region of 7 days also shows a layer of interaction but only $30 \mathrm{~nm}$ wide. The phase separation of $\mathrm{Zr}$ and $\mathrm{U}$, however, is also appreciable.

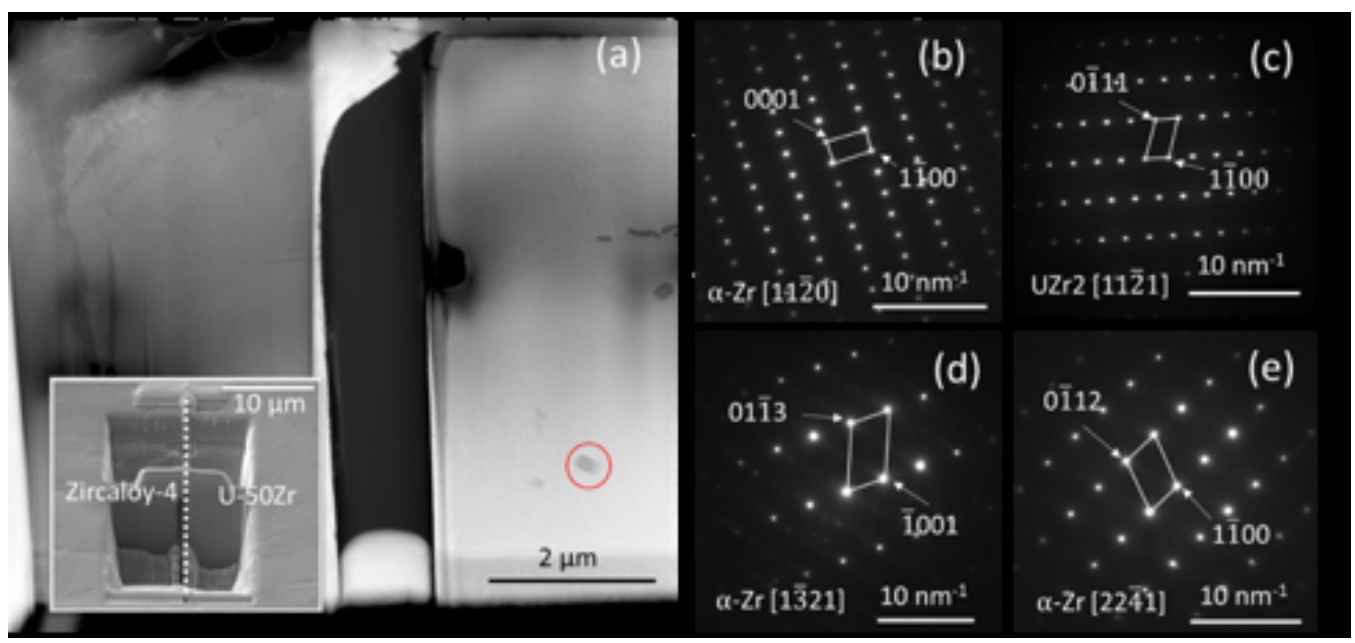

Figure 20. Transmission electron microscopy-based selected-area electron diffraction pattern indexing of the phase in the region of diffusion couple interface; (a) overview of TEM sample with site specific FIB sample preparation; (b) the Zircaloy-4 crystalizes in hexagonal crystal structure with $\mathrm{a}=3.23 \AA$ and $\mathrm{c}=$ $5.15 \AA$; (c) U-50Zr also crystalizes in hexagonal crystal structure with $\mathrm{a}=5.03 ; \AA$ and $\mathrm{c}=3.08 \AA$; (d-e) shows the precipitates, circled in (a), is $\alpha-Z r$ with a $=3.23 \AA$ and $\mathrm{c}=5.15 \AA$. The gap in the middle is formed during cooling due to weak bonding. 


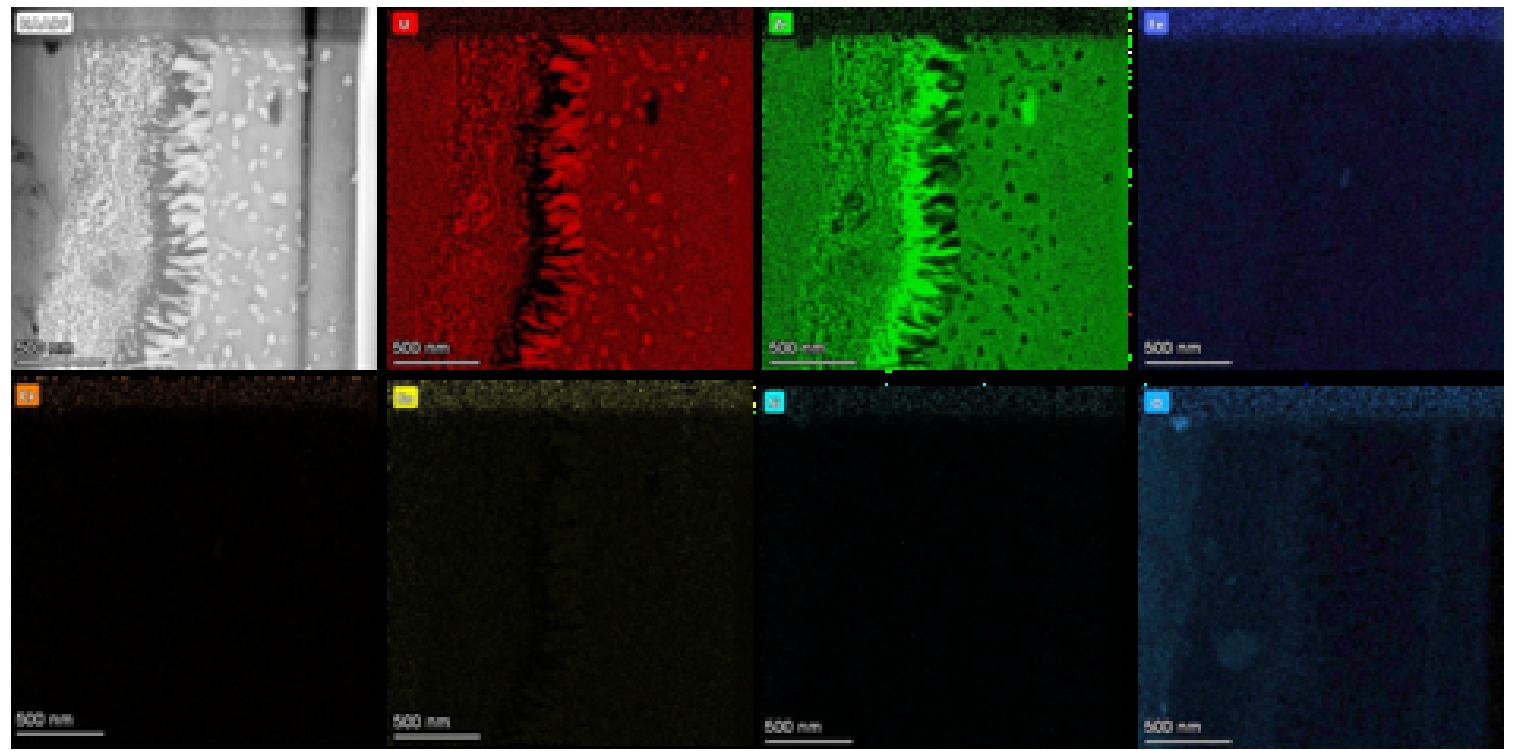

Figure 21. Scanning TEM element mapping across the diffusion interaction region of the 28-day sample. Results indicate the formation of a U-rich band. Those U phases exists as particles, columnar grains, and precipitates. $\mathrm{Fe}, \mathrm{Cr}$, and $\mathrm{Sn}$ has little contribution. Oxygen has slightly higher concentration at the outmost interaction layer.

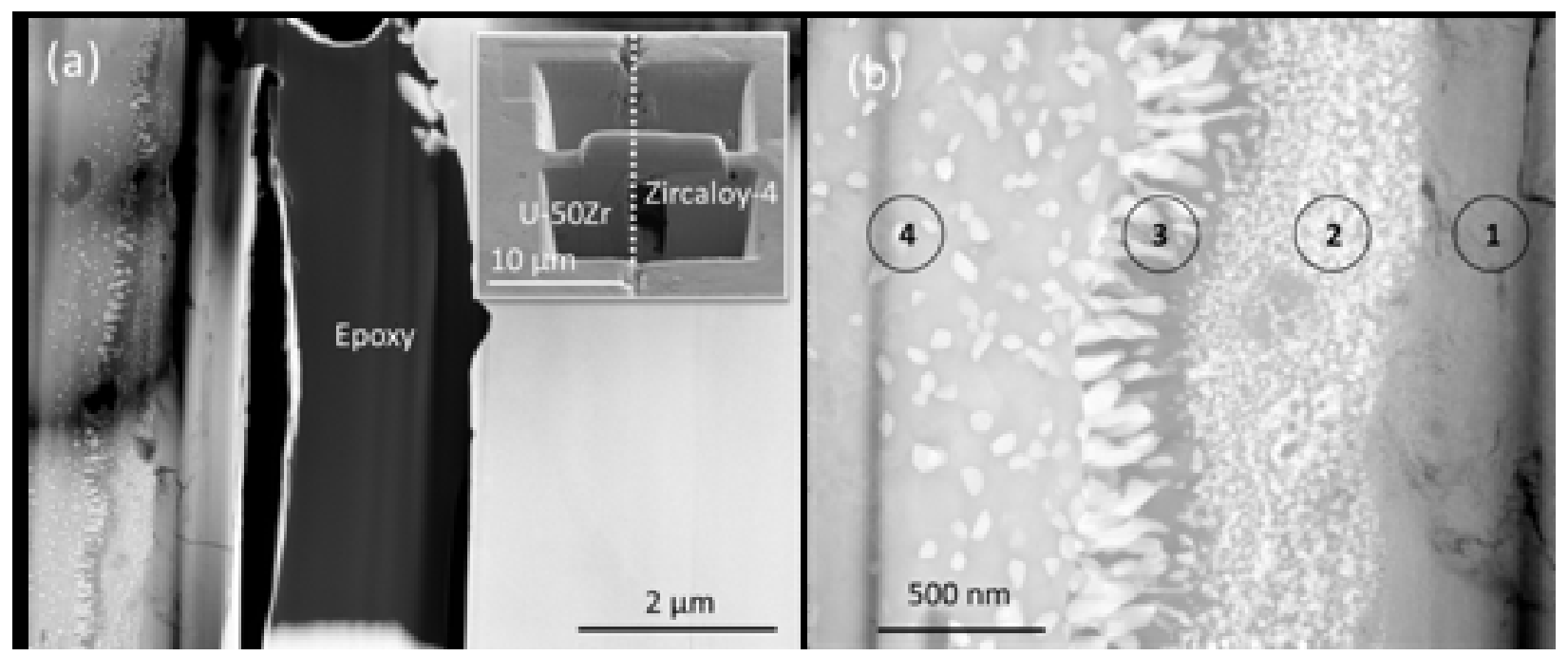

Figure 22. (a) Overview of TEM sample prepared from a 28-day diffusion couple shows evident interaction inside the U-50Zr side; (b) high-angle annular dark field image shows the interaction region can be divided into four layers with layer 1 featured by $(\mathrm{Zr} 0.7 \mathrm{U} 0.25 \mathrm{Sn} 0.03 \mathrm{Cr} 0.02) \mathrm{O} 2$ nanocrystals, layer 2 by high-density $\alpha-U$ particles in a $Z r$ matrix; layer 3 by columnar $\alpha-U$ grains growing towards the interface, and layer 4 with $\alpha-U$ precipitates embedded in $U-50 Z r$ matrix with subdivided grains. 


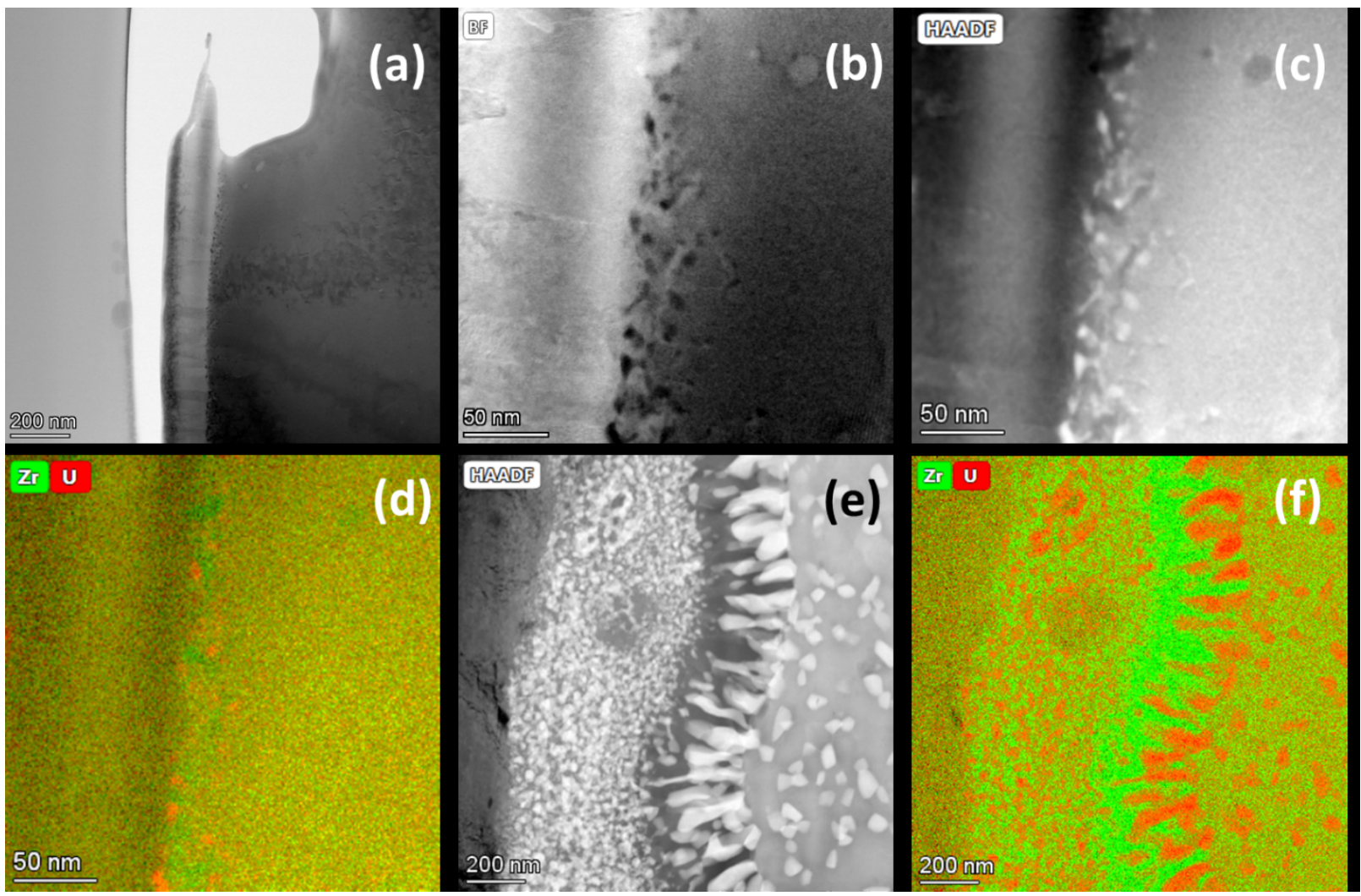

Figure 23. A comparison of 7 days $(\mathrm{a}-\mathrm{d})$ and 28 days $(\mathrm{e}-\mathrm{f})$ diffusion couples. Although columnar grains also formed on the diffusion interface (as highlighted in b), it shows little chemical variation compared with 28-day sample. However, the U-rich particles in a Zr-rich matrix is clearly shown in a band $30 \mathrm{~nm}$ wide, much narrower than 28-day sample.

\subsection{Thermophysical Property Characterizations}

The phase transition temperatures for the as-cast U-50wt.\%Zr sample are shown in Figure 24. Upon heating two phase transitions are detected with onset temperatures of $485^{\circ} \mathrm{C}$ and $606^{\circ} \mathrm{C}$, respectively. The prior transition (with an onset temperature of $485^{\circ} \mathrm{C}$ ) appears exothermic in nature, however, extremely faint in magnitude. The latter phase transition is strongly endothermic in nature with a distinct peak starting at $606^{\circ} \mathrm{C}$ and ending at $622^{\circ} \mathrm{C}$, and with a formation enthalpy of $38.4 \mathrm{~J} \mathrm{~g}^{-1}$. Upon cooling, only the latter phase transition is detected with an onset and end temperatures of $574^{\circ} \mathrm{C}$ and $603^{\circ} \mathrm{C}$, respectively. 


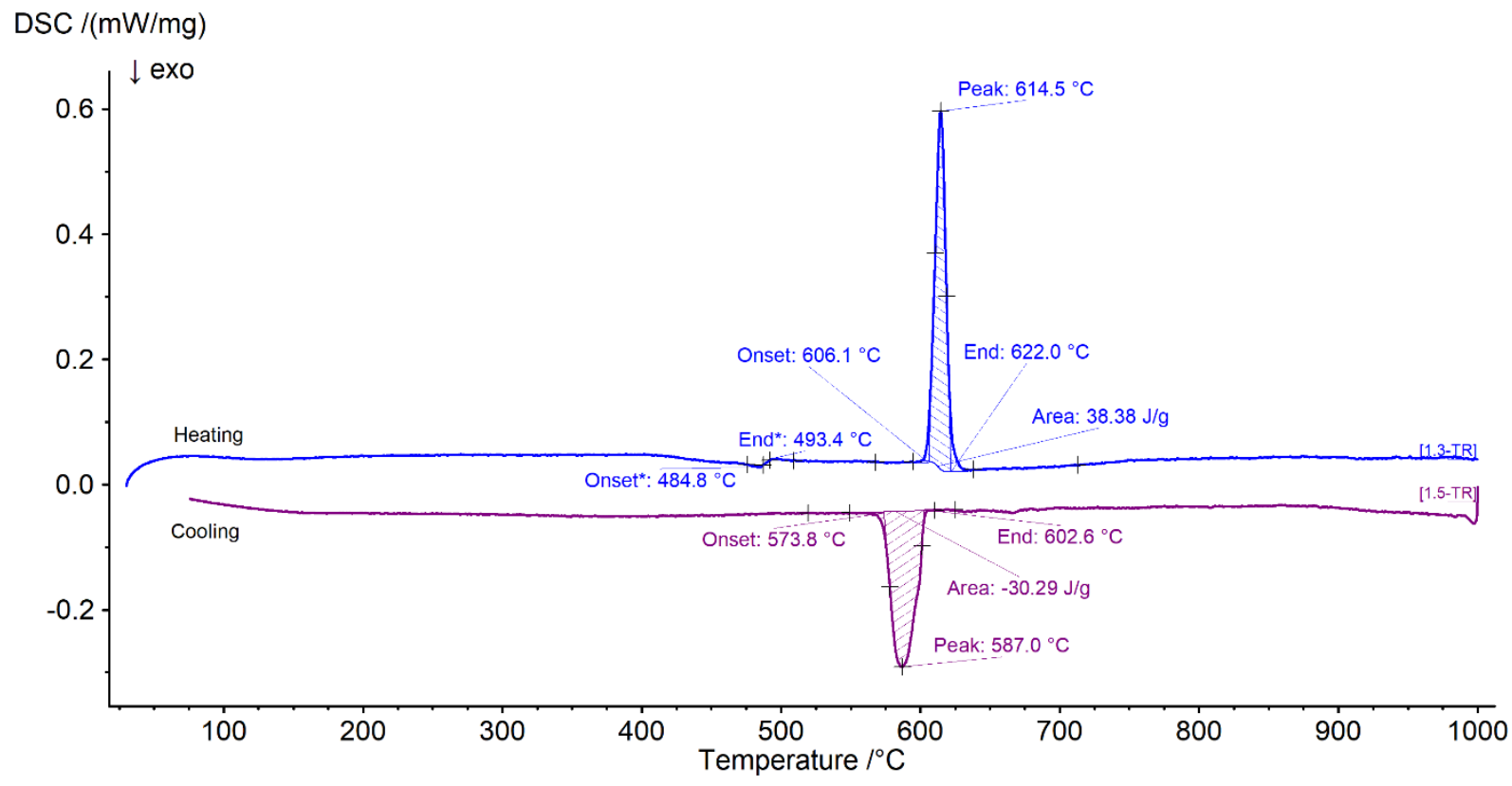

Figure 24. DSC signal as a function of temperature showing upon heating (top curve) and cooling (bottom curve). The onset and end temperatures have been identified for the corresponding phase transformations as well as the respective formation enthalpies (presented as peak areas).

The thermal diffusivity results of as-cast U-50wt.\%Zr are shown in Figure 25. The values follow a linear trend at lower temperatures, varying from $4.2 \mathrm{~mm}^{2} \mathrm{~s}^{-1}$ at $100^{\circ} \mathrm{C}$ to $6.6 \mathrm{~mm}^{2} \mathrm{~s}^{-1}$ at $450^{\circ} \mathrm{C}$. As the temperature increases up to $591^{\circ} \mathrm{C}$ thermal diffusivity remains nearly invariant followed by a significant increase up to approximately $9.9 \mathrm{~mm}^{2} \mathrm{~s}^{-1}$ at $620^{\circ} \mathrm{C}$. Subsequently, thermal diffusivity continues to increase linearly with respect to temperature reaching $11.3 \mathrm{~mm}^{2} \mathrm{~s}^{-1}$ at $800^{\circ} \mathrm{C}$.

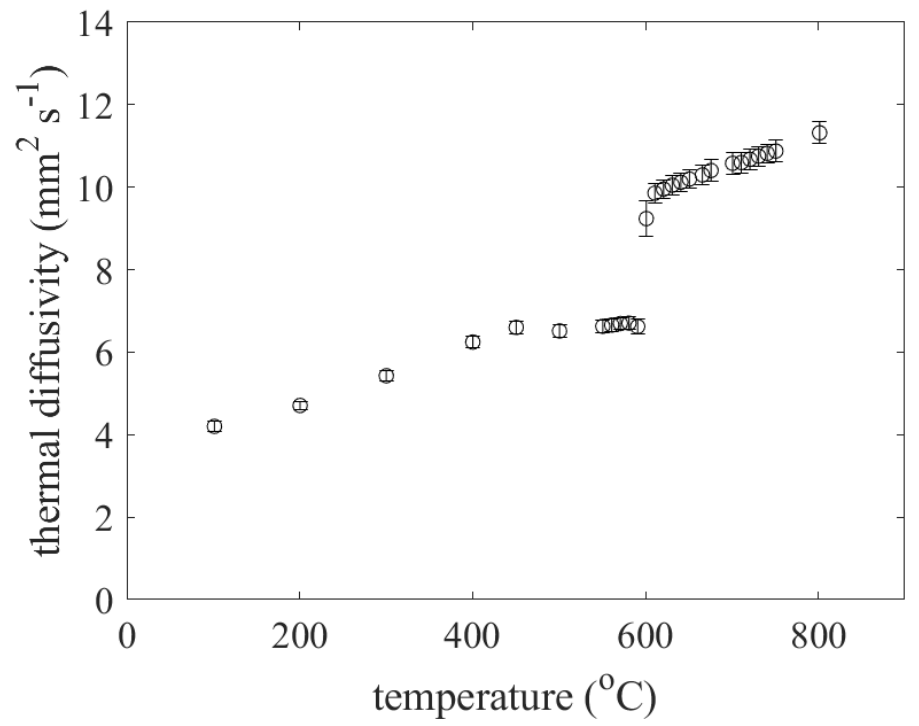

Figure 25 . Thermal diffusivity of as-cast $\mathrm{U}-50 \mathrm{wt} . \% \mathrm{Zr}$ as a function of temperature. The measurements are performed upon heating. 
The specific heat capacity measurements for as-cast U-50wt.\%Zr (obtained upon heating) are shown as a function of temperature in Figure 26. The data throughout the phase transition temperature ranges are not shown due to an erroneous linear combination between the material's specific heat capacity and transformation enthalpy quantities. The specific heat capacity of the as-cast U-50wt.\% Zr can be characterized by three distinct temperature ranges. From $100^{\circ} \mathrm{C}$ to $400^{\circ} \mathrm{C}$ the value of this property varies between $0.2 \mathrm{~J} \mathrm{~g}^{-1} \mathrm{~K}^{-1}$ to $0.23 \mathrm{~J} \mathrm{~g}^{-1} \mathrm{~K}^{-1}$. Between $400^{\circ} \mathrm{C}$ to $600^{\circ} \mathrm{C}$, above the first phase transition temperature, specific heat exhibits a slight decrease from $0.19 \mathrm{~J} \mathrm{~J} \mathrm{~g}^{-1} \mathrm{~K}^{-1}$ to $0.16 \mathrm{~J} \mathrm{~g}^{-1} \mathrm{~K}^{-1}$. Above the second phase transition end temperature $\left(622^{\circ} \mathrm{C}\right)$, this property increases from $0.1 \mathrm{~J} \mathrm{~g}^{-1} \mathrm{~K}^{-1}$ gradually to $0.17 \mathrm{~J} \mathrm{~g}^{-1} \mathrm{~K}^{-1}$ at $800^{\circ} \mathrm{C}$ and remains invariant up to $900^{\circ} \mathrm{C}$.

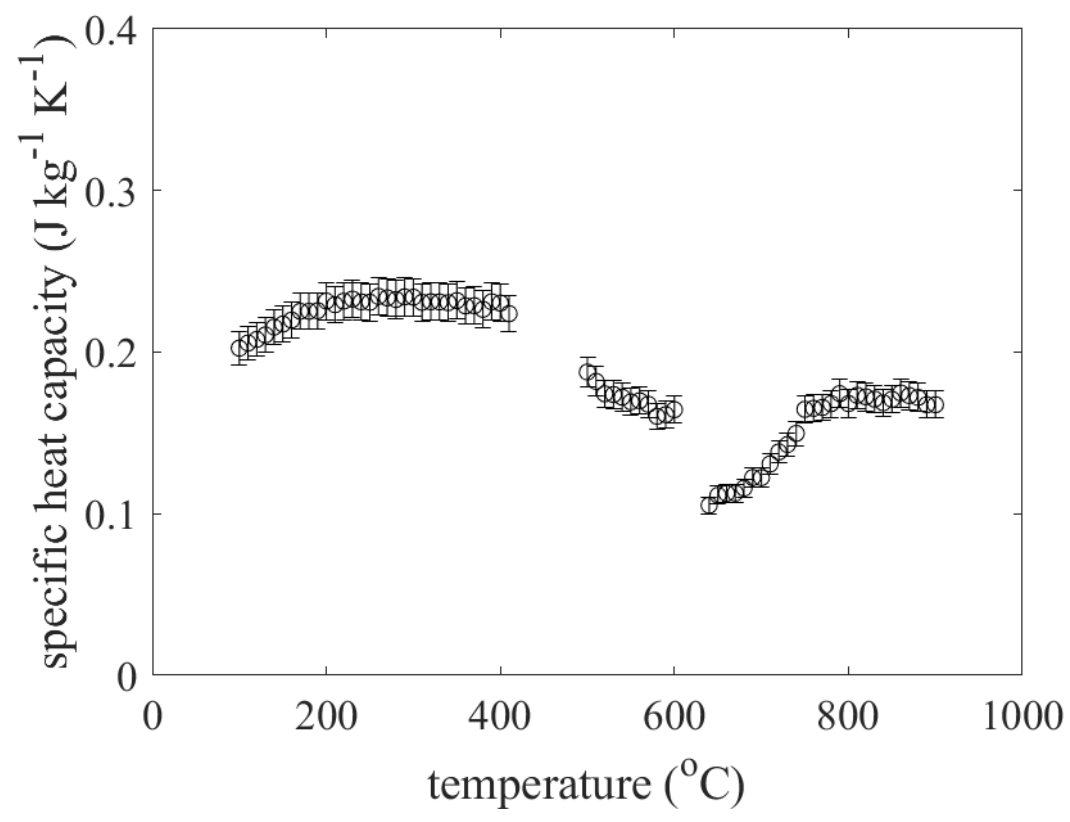

Figure 26. Specific heat capacity of as-cast U-50wt.\% $\mathrm{Zr}$ as a function of temperature. The temperatures at which phase transitions occur have been omitted. The measurements are performed upon heating.

The linear thermal expansion of as-cast U-50wt.\%Zr is shown in Figure 27. The material's linear thermal expansion exhibits a linear trend with respect to temperature-from $0.06 \%$ at $100^{\circ} \mathrm{C}$ to $0.64 \%$ at $588^{\circ} \mathrm{C}$, respectively. As the temperature increases further, a rapid length (and hence volume) change is observed up to $607^{\circ} \mathrm{C}$ with linear thermal expansion reaching $0.81 \%$. Subsequently, the sample continues to expand linearly with increasing temperature reaching a length change of $1.39 \%$ at $1000^{\circ} \mathrm{C}$. 


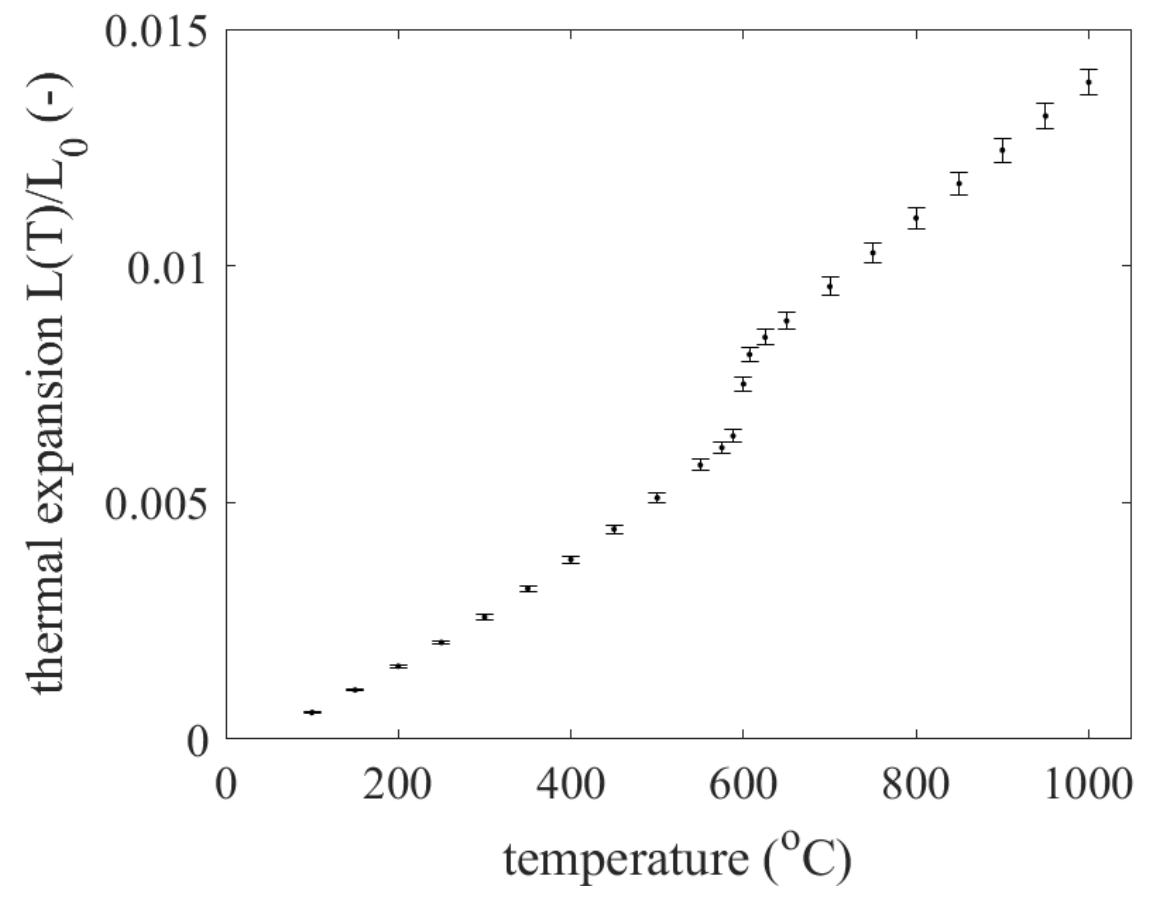

Figure 27. Thermal expansion of as-cast $\mathrm{U}-50 \mathrm{wt} . \% \mathrm{Zr}$ as a function of temperature. The measurements are performed upon heating.

Figure 28 shows the thermal conductivity as a function of temperature for as-cast U-50 wt.\%Zr. Thermal conductivity increases from $8.1 \mathrm{~W} / \mathrm{m} / \mathrm{K}$ to $13.6 \mathrm{~W} / \mathrm{m} / \mathrm{K}$ between 100 to $400^{\circ} \mathrm{C}$. Subsequently, showing a gradual decrease in this property up to $600^{\circ} \mathrm{C}$, reaching a minimum of approximately $9.8 \mathrm{~W} / \mathrm{m} / \mathrm{K}$, followed by an increase up to $800^{\circ} \mathrm{C}$ at $17.4 \mathrm{~W} / \mathrm{m} / \mathrm{K}$. 


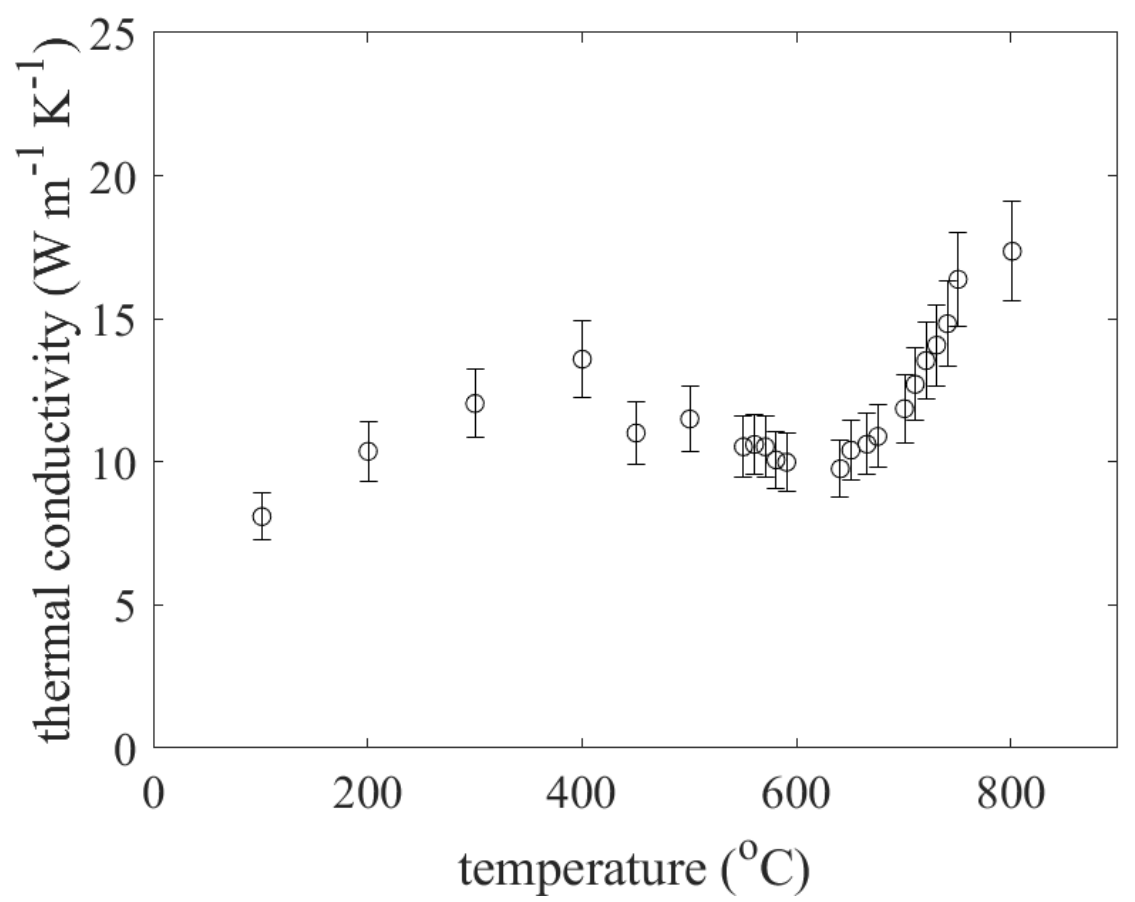

Figure 28. Thermal conductivity of as-cast $\mathrm{U}-50 \mathrm{wt} . \% \mathrm{Zr}$ as a function of temperature. The measurements are performed upon heating.

\section{CONCLUDING DISCUSSIONS}

\subsection{Thermophysical Property Characterization}

The current study has measured various thermophysical properties of as-cast U-50wt.\%Zr from $100^{\circ} \mathrm{C}$ up to and above $800^{\circ} \mathrm{C}$ - phase transition temperatures, specific heat capacity, thermal diffusivity, thermal expansion, and thermal conductivity. The DSC results show the presence of two phase transitions upon heating while only one phase transition is detected upon cooling. The reversible phase transition (with an onset temperature of $606^{\circ} \mathrm{C}$ upon heating) is consistent with the available U-Zr phase diagrams [25] and corresponds to a $\delta \rightarrow \gamma$ transition. The additional phase transition (which occurs above $400^{\circ} \mathrm{C}$ upon heating, however, is not detected upon cooling) is consistent with the presence of non-equilibrium phases in the as-cast microstructure. These are likely a result of the rapid cooling rates used during the fabrication process (water quenching). These non-equilibrium phases could be of martensitic nature which is in line with the current SEM results (lath/needle-like structures) as well as previous studies on as-cast U-6wt.\% by Kaity et al. [14]. These previous studies show similar microstructural patterns and demonstrate the disappearance of the lower temperature DSC peaks after prolonged annealing. The presence of these phases could explain the significant changes occurring in specific heat, thermal diffusivity, and thermal conductivity between $400^{\circ} \mathrm{C}$ and approximately $600^{\circ} \mathrm{C}$. Future work would focus on additional measurements taken not only upon heating but also upon cooling. Additionally, various annealing temperatures and times would be explored to homogenize the as-cast samples prior to characterizing the thermophysical properties. This would help verify whether the trends observed in the current study are related to a reversible or a non-equilibrium process.

\subsection{Mechanical Assessment}

The current study investigated the mechanical properties of U-50Zr using nanoindentation techniques. We identified that the yield stress of the U-50Zr (arc-melted) is almost half of the yield stress of a typical fresh cold-worked stress annealed (CW SA) Zircaloy (550-650 MPa). Also, nanoindentation-estimated 
creep rates were significantly high. Although more systematic studies must be performed, these results indicates that fuel performance will be affected with the use of U-50Zr. Since, the fuel is not hard, the cladding will impose compression on the fuel which will cause local fuel hardening, but this effect will likely not significant since the local burnup at the fuel periphery is high, and these regions are likely be soft due to the high-burnup structure. On the other hand, softer fuel is likely improving the pellet-clad mechanical interaction (PCMI) behavior of the fuel. The fuel will not have strength to impose a significant strain-induced deformation on the cladding and will not cause cladding failure.

\subsection{Diffusion Couple}

Investigating the intermixing behavior of U-50Zr fuel with Zircaloy-4 cladding provides critical information on the formation of PCI layer during LWR operation. Even though, diffusion couples were autoclaved for a limited time, the characterization of the interaction layer indicated that U-50Zr is likely exhibiting a stable performance. Importantly, zirconium oxide layer was formed once the pellet-cladding interaction occurred. We anticipate that uranium selectively interacted with the oxygen in the Zircaloy-4 and formed a protective layer. This layer may improve the transient behavior of the fuel and the positively impact the load follow procedures in PWRs. We suggest more research is needed to elucidate the nature of the interaction layer of U-50Zr and Zircaloy-4.

It appears that presence of hydrogen improved the pellet-cladding interaction. Remember that, diffusion couples were tested at $375^{\circ} \mathrm{C}$ where all the hydrogen was dissolved in the parent $\mathrm{Zr}$ matrix of the Zircaloy-4. It is known the solute hydrogen significantly expands the Zr lattice [14]; this expansion may yield better surface contact. However, more research is to be conducted to understand the underlying mechanism, especially from the chemistry perspective.

Performing cladded Zr-50 fuel corrosion tests with modern Zr-Nb alloys at PWR operating conditions will likely result in more detailed data. Noting that, the current study excluded irradiation effects where the formation of PCI layer may be affected.

\subsection{Summary Statement}

Various thermophysical and mechanical properties of as-cast U-50Zr have been measured between $100^{\circ} \mathrm{C}$ and $800^{\circ} \mathrm{C}$, namely phase transition temperatures, thermal diffusivity, specific heat, thermal expansion, thermal conductivity, hardness, elastic modulus, estimated yield strength, and preliminary creep rates. The delta to gamma transition onset and end temperatures have been measured at $606^{\circ} \mathrm{C}$ and $622^{\circ} \mathrm{C}$, respectively. An onset of a weak exothermic phase transition is observed between $400^{\circ} \mathrm{C}$ and $500^{\circ} \mathrm{C}$ (only detected upon heating in the DSC curves). This transition may be representative of a martensitic transformation formed during the fabrication process (water quenching). This could explain the abrupt changes observed in specific heat capacity, thermal diffusivity and thermal conductivity between $400^{\circ} \mathrm{C}$ and $600^{\circ} \mathrm{C}$; however, additional thermal cycling and annealing studies would be necessary to confirm these preliminary hypotheses. Mechanical testing validated previous estimates that the fuel would be relatively soft and thus susceptible to creep down effects and unlikely to induce negative changes to PCMI behavior. Lastly, initial studies on chemical interactions from hydriding effects have shown U-50Zr to have remained stable and for adequate protective oxide layers to have formed. These results should be used as a guide for further investigation into the use of U-50Zr fuel forms in LWR environments.

\section{REFERENCES}

1. Akabori, M, et al. 1995. "The Lattice Stability and Structure of $\delta-\mathrm{UZr}_{2}$ at Elevated Temperatures." Journal of Physics: Condensed Matter 7: 8249. https://iopscience.iop.org/article/10.1088/0953-8984/7/43/005.

2. Deng, Y. 2019. "Utilization of 3D Fuel Modeling Capability of BISON to Derive New Insights in Performance of Advanced PWR Fuel Concepts." 516: 271-288. https://doi.org/10.1016/j.jnucmat.2019.01.032 
3. Sangjoon, A., S. Irukuvarghula, S. M. McDeavitt. 2016. "Microstructure of $\alpha-U$ and $\delta$-UZr2 Phase Uranium-Zirconium Alloys Irradiated with 140-keV He+ Ion-Beam." Journal of Alloys and Compounds 681: 6-11. https://doi.org/10.1016/j.jallcom.2016.04.219.

4. Idaho National Laboratory. n.d. "MOOSE Framework. "Thermal Properties for UPuZr Fuel." Last accessed September 29, 2021. https://mooseframework.inl.gov/bison/source/materials/UPuZrThermal.html. M

5. Popov, S. G. 2000. "Thermophysical Properties of MOX and $\mathrm{UO}_{2}$ Fuels Including the Effects of Irradiation.” ORNL/TM-2000/351, Oak Ridge National Laboratory.

6. McConn, R.J. Jr. "Compendium of Material Composition Data for Radiation Transport Modeling." PNNL-15870, Pacific Northwest National Laboratory.

7. Wikipedia. n.d. "Uranium dioxide." Last modified September 23, 2021. https://en.wikipedia.org/wiki/Uranium_dioxide.

8. Janney, D. 2017. “Metallic Fuels Handbook, Part 1.” INL/EXT-15-36520 Rev. 2 Part 1, Idaho National Laboratory.

9. Argonne National Laboratory. 2011. "Nuclear Fuel." https://www.ne.anl.gov/pdfs/nuclear/nuclear_fuel_yacout.pdf

10. Argonne National Laboratory - West. 1980. "EBR-II: Sixteen Years of Operation.” ANL-0001, Argonne National Laboratory - West. https://inldigitallibrary.inl.gov/Reports/ANL-0001.pdf.

11. Yao, T., A. Sen, A. Wagner, F. Teng, M. Bachhav, A. Ei-Azab, D. Murray, J. Gan, D.H. Hurley, J.P. Wharry, M.T. Benson, L. He. 2021. "Understanding spinodal and binodal phase transformations in U-50Zr.” Materialia 16: 101092. https://doi.org/10.1016/j.mtla.2021.101092.

12. Cinbiz, M.N., X. Hu, K. Terrani. 2018. "Thermal expansion behavior of $\delta$-zirconium hydrides: Comparison of $\delta$ hydride powder and platelets." Journal of Nuclear Materials 509: 566-576. https://doi.org/10.1016/j.jnucmat.2018.07.026.

13. Cinbiz, M.N., D.A. Koss, A.T. Motta. 2016. "The influence of stress state on the reorientation of hydrides in a zirconium alloy." Journal of Nuclear Materials 477: 157-164. https://doi.org/10.1016/j.jnucmat.2016.05.013.

14. Cinbiz, M.N., D.A. Koss, A.T. Motta, J.-S. Park, J.D. Almer. 2017. "In situ synchrotron X-ray diffraction study of hydrides in Zircaloy-4 during thermomechanical cycling." Journal of Nuclear Materials 487: 247-259. https://doi.org/10.1016/j.jnucmat.2017.02.027.

15. AZO Materials. n.d. "Super Alloy KOVAR (UNS K94610).” Last accessed on September 29, 2021. https://www.azom.com/article.aspx?ArticleID=9572.

16. Gao, X.L. 2006. "An expanding cavity model incorporating strain-hardening and indentation size effects.” International Journal of Solids and Structures 43(21): 6615-6629. https://doi.org/10.1016/j.ijsolstr.2006.01.008.

17. Gao, X.L., X.N. Jing, G. Subhash. 2006. "Two new expanding cavity models for indentation deformations of elastic strain-hardening materials." International Journal of Solids and Structures 43(7): 2193-2208. https://doi.org/10.1016/j.ijsolstr.2005.03.062.

18. Bower, A., N.A. Fleck, A. Needleman, N. Ogbonna. 1993. "Indentation of a power law creeping solid." Proceedings of the Royal Society of London. Series A: Mathematical and Physical Sciences 441(1911): 97-124. https://doi.org/10.1098/rspa.1993.0050.

19. Mulhearn, T., D. Tabor. 1960. "Creep and hardness of metals-a physical study." Journal of the Institute of Metals 89(1): 7-12. 
20. Choi, I.C., B.G. Yoo, Y.-J. Kim, J.I. Jang. 2012. “Indentation creep revisited.” Journal of Materials Research 27(1): 3.https://doi.org/10.1557/jmr.2011.213.

21. Lee, D.H., M.Y. Seok, Y. Zhao, I.C. Choi, J. He, Z. Lu, J.Y. Suh, U. Ramamurty, M. Kawasaki, T.G. Langdon, J.I. Jang. 2016. "Spherical nanoindentation creep behavior of nanocrystalline and coarse-grained CoCrFeMnNi high-entropy alloys." Acta Materialia 109: 314-322. https://doi.org/10.1016/j.actamat.2016.02.049.

22. Ginder, R.S., W.D. Nix, G.M. Pharr. 2018. “A simple model for indentation creep.” Journal of the Mechanics and Physics of Solids 112: 552-562. https://doi.org/10.1016/j.jmps.2018.01.001.

23. Khanolkar, A., T. Yao, Z. Hua, C.A. Dennett, S.J. Reese, R.S. Schley, L. He, J.R. Kennedy, D.H. Hurley. 2021. "In situ monitoring of microstructure evolution during thermal processing of uranium-zirconium alloys using laser-generated ultrasound." Journal of Nuclear Materials 553: 153005. https://doi.org/10.1016/j.jnucmat.2021.153005.

24. Rough, F.A. 1955. “An evaluation of data on uranium-zirconium alloys.” BMI-1030. Battelle Memorial Inst. https://doi.org/10.2172/4352223.

25. Janney, D.E., S.L. Hayes. 2918. "Experimentally known properties of U-10Zr alloys: A critical review." Nuclear Technology 203(2): 109-128. https://doi.org/10.1080/00295450.2018.1435137.

26. G L Hofman, L C Walters, and T H Bauer. Metallic fast reactor fuels. Progress in Nuclear Energy, 31(1-2):83-110, January 1997

27. M. C. Billone, Y. Y. Liu, E. E. Gruber, T. H. Hughes, and J. M. Kramer. Status of Fuel Element Modeling Codes for Metallic Fuels. In Proceedings American Nuclear Society International Conference on Reliable Fuels for Liquid Metal Reactors. Tucson, Arizona, September 7-11 1968.

28. H. Savage. The heat content and specific heat of some metallic fast-reacdtor fuels containing plutonium. Journal of Nuclear Materials, 25:583-594, 2006. doi:10.1016/0022-3115(68)90168-2.

29. R. S. Barnes. A Theory of Swelling and Gas Release for Reactor Materials. Journal of Nuclear Materials, 11:135-148, 1964.

30. Pavel Medvedev. Fuel performance modeling results for representative FCRD irradiation experiments: projected deformation in the annular AFC-3A U-10Zr fuel pins and comparison to alternative designs. Technical Report INL/EXT-12-27183 Revision 1, Idaho National Laboratory, 2012.

31. A. Karahan and J. Buongiorno. A new code for predicting the thermo-mechanical and irradiation behavior of metallic fuels in sodium fast reactors. Journal of Nuclear Materials, 396:283-293, 2010.

32. Aydin Karahan. Modeling of thermo-mechanical and irradiation behavior of metallic and oxide fuels for sodium fast reactors. PhD thesis, Massachusetts Institute of Technology, Jun 2009. URL: https://tinyurl.com/y72vqvbn. 


\section{Appendix A: BISON Simulations}

This section will contain the results of converting a BISON assessment case of a LWR fuel rod model from $\mathrm{UO}_{2}$ ceramic fuel to $\mathrm{U}-50 \mathrm{Zr}$ metallic fuel. The reader is referred to the BISON user manual for details on the models used in this simulation. Generally, the models for U-Zr used in this series of simulations are based upon $\mathrm{U}-\mathrm{Pu}-\mathrm{Zr}$ models developed for $\mathrm{U}-10 \mathrm{Zr}$ and $\mathrm{U}-\mathrm{Pu}-\mathrm{Zr}$ systems from the EBR-II fuel tests. Extension of these models into the U-50Zr system are highly suspect and should highlight the critical need for irradiation testing if this fuel type is to be pursued.

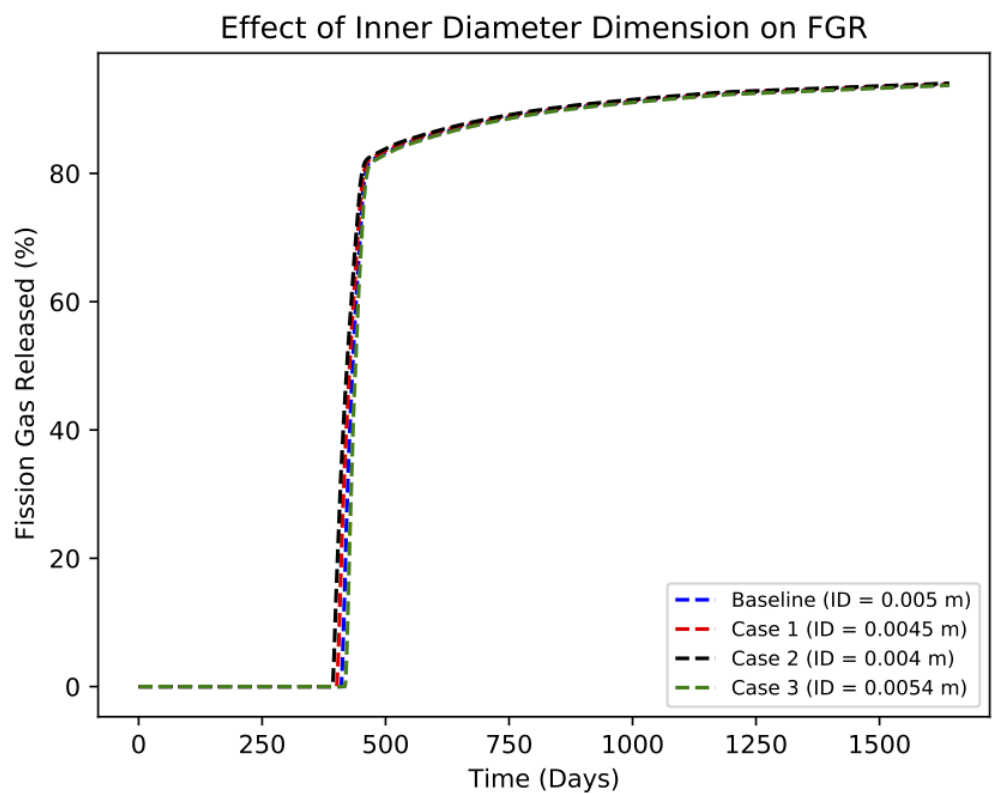

Figure 29: The total fission gas release of a fuel with varying inner diameter of an annular U-50Zr fuel. The fission gas release model is assumes pore connectivity at 2 atom \% burnup, at which point $80 \%$ of the fission gas produced is released.

The fission gas release model is based upon the Hoffman model [26].

$$
\begin{aligned}
& G_{\text {released }}(t+\Delta t)= \begin{cases}0 & p<p_{\text {critical }} \\
0.8 G_{\text {produced }}(t+\Delta t) & p=p_{\text {critical }} \\
G_{\text {released }}(t)+\left[G_{\text {produced }}(t+\Delta t)-G_{\text {produced }}(t)\right] & p>p_{\text {critical }}\end{cases} \\
& \qquad G_{\text {produced }}(t+\Delta t)=G_{\text {produced }}(t)+\dot{F}_{\text {avg }} \Delta t \gamma / N_{A}, \\
& \quad \dot{F}_{\text {ave }}=\frac{\dot{F}(t)+\dot{F}(t+\Delta t)}{2}
\end{aligned}
$$




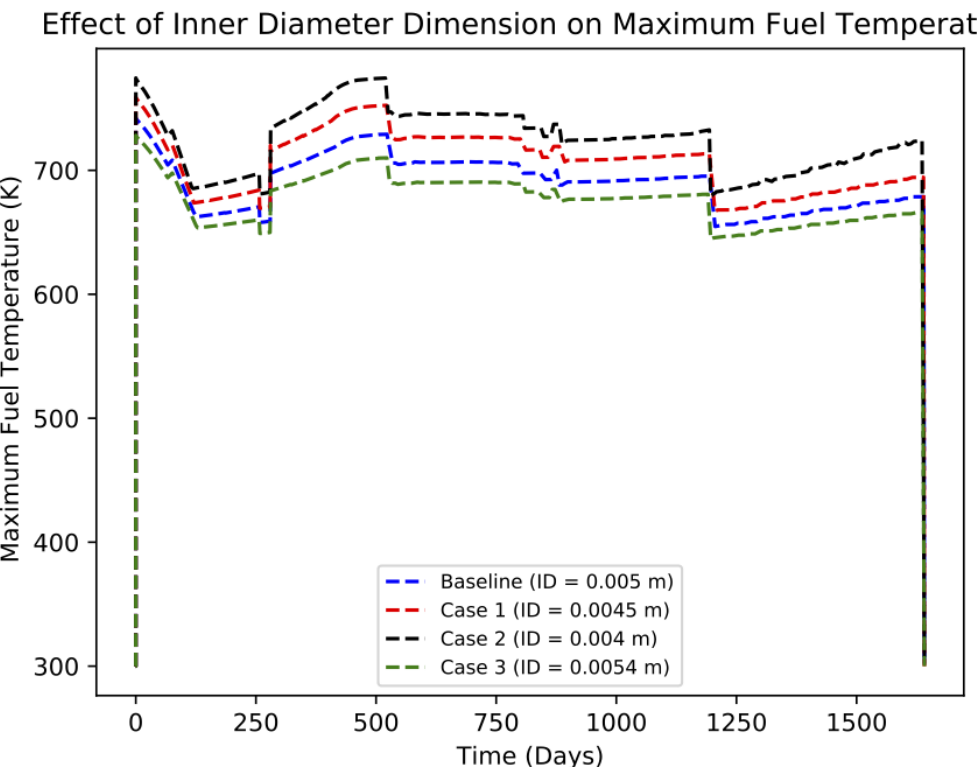

Figure 30: Peak fuel temperature as a function of burnup for varying inner diameter of annular U-50Zr fuel. This model is based upon the $U$

The thermal properties models for the BISON simulation run utilize the Billon thermal conductivity model [27] and the Savage heat capacity model [28]. Equations and additional considerations are shown in the Bison Code Manual.

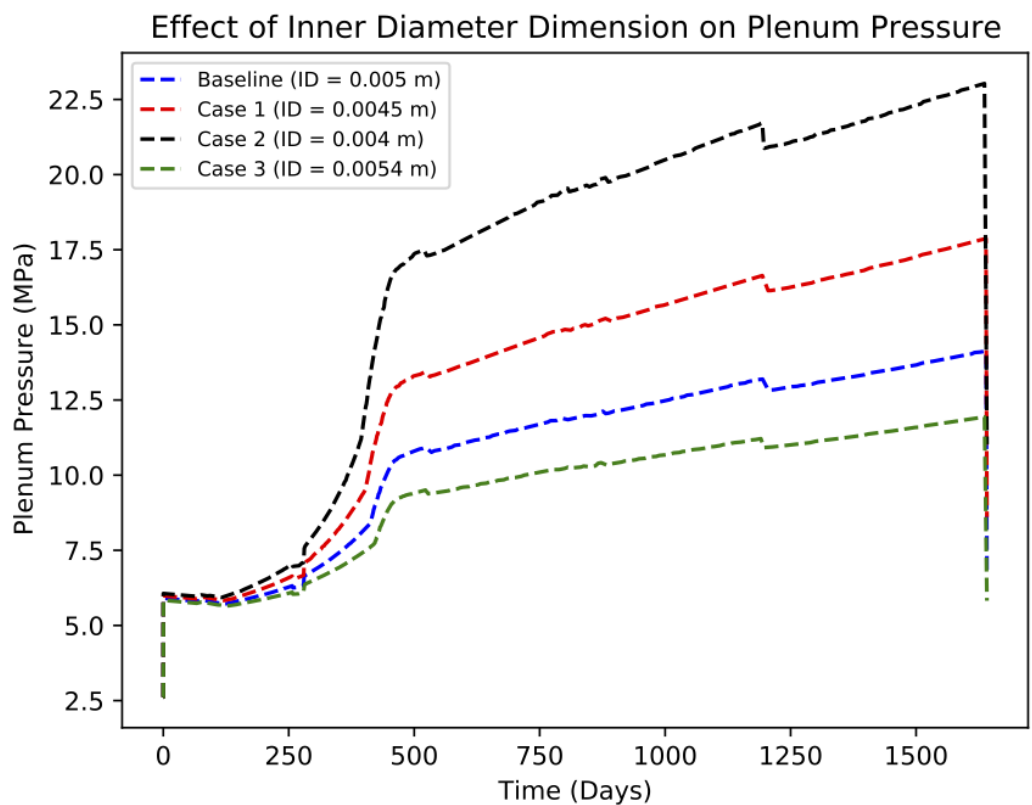

Figure 31:The effective of the inner diameter of an annular fuel on the plenum pressure. This model assumes the fission gas release shown in Figure 29 for the increase in pressure around 300 days.

The plenum pressure is calculated by the temperatures from Figure 30 and the gas produced in Figure 29. The swelling of the fuel is managed under U-10Zr assumptions [29-32] and would require significant modification for the U-50Zr system.

Additionally, the U-Zr system is prone to thermal induced de-mixing of the primary constituents, also known as constituent redistribution. While the fundamental understanding of the process is continuously 
being pursued, there is little study of the phenomena in U-50Zr alloys. Should this phenomena be of interest, or appear during irradiation testing, where thermal gradients are large enough to produce the effect, the following description is provided to inform the reader of how BISON describes the thermodynamics of constituent redistribution.

The flux of zirconium, in U-Zr systems, across a thermal gradient is given by the following equation where $\mathrm{D}$ is the interdiffusion coefficient of $\mathrm{Zr}, \mathrm{C}_{0}$ is the density of lattice sites, $\chi$ is the concentration of $\mathrm{Zr}$, and $\mathrm{Q}$ is the heat of transport of $\mathrm{Zr}$ :

$$
\overrightarrow{J_{Z r}}=-c_{0} D\left(\nabla \chi_{\mathrm{zr}}+\chi_{Z r}\left(1-\chi_{Z r}\right) \frac{Q^{*}}{R T^{2}} \nabla T\right.
$$

It is again noted that BISON theory was developed for $\mathrm{UO}_{2}$ ceramic fuel. While much has been implemented for the U-Zr system, it is heavily focused on U-Pu-Zr and U-10Zr alloys with minimal investigation into the $\mathrm{U}-50 \mathrm{Zr}$ system, probable until irradiation testing of $\mathrm{U}-50 \mathrm{Zr}$ is immanent. However, the $\delta-\mathrm{UZr}_{2}$ phase is present in these systems at a lower percent $\mathrm{Zr}$, near $43 \mathrm{at} . \%$. As such, the existing BISON framework may be suitable for "first look" approximations in fuel performance. The most sensitive variables to the extrapolation to U-50Zr are hypothesized to be fission gas release, as the current model is dominated by $\alpha-U$ and it's subsequent material properties and fission density, and fuel swelling, as defect manifestation and crystallographic dependencies varies greatly between orthorhombic $\alpha-U$ and hexagonal $\delta-\mathrm{UZr}_{2}$. Additional foundations for fundamental modeling can be found in the BISON theory manual and include a thermal conductivity model, heat capacity calculations, thermal and irradiation creep, thermal expansion, and mechanical properties.

Acknowledgements: Albert Casagranda for running BISON simulations during the FMEA/PIRT period of this project and previous assistance advising on U-Zr behaviors. 